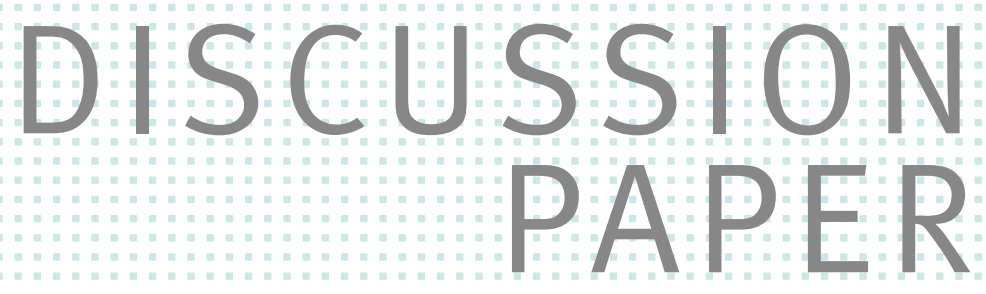

/ / ROBERT GERMESHAUSEN, SVEN HEIM, AND ULRICH J. WAGNER

Support for Renewable Energy: The Case of Wind Power 


\title{
Support for Renewable Energy: The Case of Wind Power*
}

\author{
Robert Germeshausen $^{\dagger} \quad$ Sven Heim ${ }^{\ddagger} \quad$ Ulrich J. Wagner ${ }^{\S}$
}

August 27, 2021

\begin{abstract}
Successful decarbonization of the electricity sector hinges on the support of the public, which is at risk when electricity generation emits local externalities. This paper estimates the impact of wind turbine deployment on granular measures of revealed preferences for renewable electricity in product and political markets. We address endogenous siting of turbines with a novel IV approach that exploits quasi-experimental variation in profitability. We find that nearby wind turbines significantly reduce citizens' support, but this effect quickly fades with distance from the site. Our results shed light on how distance requirements and financial participation could enhance support for renewables.
\end{abstract}

Keywords: Renewable energy, Wind power, Public support, Elections, Externalities.

JEL Classification: D12, D72, Q42, Q50

${ }^{*}$ We thank ene't for giving us data on search queries on price comparison websites. We also thank Acxiom for giving us data on household characteristics and Verivox for providing data on actual electricity supplier switching via their price comparison website. Funding by the German Research Foundation (DFG) through CRC 884 (Project B10) is gratefully acknowledged. We thank Pierre Fleckinger, Matthieu Glachant, Paul Heim, Stephen Jarvis, Ulrich Laitenberger, Stefan Lamp, Chloé Le Coq, Mario Liebensteiner, Erik Lundin, Philipp Massier, Dennis Rickert, Simon Touboul and the audiences at the FAEE seminar, Heidelberg University, INRAE, Mannheim Energy Conference, Mannheim University, MINES ParisTech, University of Lille, University of Paris II Panthéon-Assas, Potsdam Institute for Climate Impact Research, Toulouse School of Economics and ZEW Mannheim for valuable comments.

${ }^{\dagger}$ ZEW - Leibniz Centre for European Economic Research Mannheim, Germany, Email: robert .ger meshausen@zew . de

$\ddagger$ MINES ParisTech (CERNA) - PSL, France; University of Paris II Panthéon-Assas (CRED), France, and ZEW - Leibniz Centre for European Economic Research Mannheim, Germany, Email: sven . heim@m ines-paristech.fr

\$University of Mannheim, Germany, and ZEW - Leibniz Centre for European Economic Research Mannheim, Germany, Email: ulrich.wagner@uni-mannheim.de 


\section{Introduction}

A defining characteristic of liberal societies is that public policies are based on the consent of its citizens. While the values and objectives behind such policies often find broad consensus, the concrete design is more contentious because it creates winners and losers. By denying their consent, losers may delay or block a policy despite a large positive impact on aggregate welfare. The more radical the transformation pursued by a policy is, the higher are the stakes, and hence the more crucial is a broad consensus for successful implementation.

The energy transition - i.e., the process of transforming the energy infrastructure so as to dramatically reduce its detrimental environmental impacts - is an important case in point. The global power sector heavily depends on fossil fuels that pollute ambient air and drive global climate change. Increasing the share of low-carbon, renewable energy like wind, solar or hydro power in total electricity generation is the key to mitigating both types of negative externalities. The Intergovernmental Panel on Climate Change (IPCC) estimates that limiting global warming to $1.5^{\circ} \mathrm{C}$ requires that the renewable electricity share reach 70-85 percent by 2050 (IPCC, 2018). Wind power has been attributed a dominant role in such scenarios, due to its low cost and universal availability (European Commission, 2018). Despite those virtues, harvesting wind power gives rise to negative externalities locally. Wind turbines can lower the aesthetic value of a landscape, interfere with wildlife, generate noise emissions, and reduce local property values. The discrepancy between local and global effects leads to a situation in which the deployment of wind turbines is embraced in the abstract ${ }^{1}$ yet strongly resented by local residents when concrete projects are planned - an attitude often referred to as not-in-my-backyard (NIMBY). Given the massive scale at which wind power is needed to replace conventional generation capacity, wind turbines will soon affect a large proportion of citizens in densely populated countries. If NIMBY attitudes towards wind turbines scales up with their deployment, this might lead to broad opposition and, hence, threaten the success of the energy transition.

${ }^{1}$ See, e.g., Renewable Energy Agency (2016). 
This paper empirically estimates local opposition to wind turbine deployment using data from Germany, a leading country in the uptake of wind energy worldwide. Thanks to a generous and prolonged subsidy program, the share of wind power in Germany's gross electricity consumption has grown from 1.7 percent in 2000 to 6.2 percent in 2010, and as much as 18.7 percent in 2020 (BMWi, 2021). Total installed capacity in Germany is surpassed only by China and the U.S., though the wind share in the electricity mix is still less than half in those countries. ${ }^{2}$ In recent years, the pace of expansion has slowed substantially, threatening to set back Germany's trajectory towards achieving carbon neutrality. ${ }^{3}$ Plans to install new wind turbines have been met with substantial opposition from local residents who often launch litigation against them. ${ }^{4}$ To understand how the deployment of wind turbines affects citizens' support for green electricity, we analyze two granular, revealed-preference measures: (i) search queries for renewable electricity tariffs on price comparison websites and (ii) vote shares for the Green Party which started the wind boom two decades ago.

Our research design exploits variation in the construction of new wind turbines to identify the impact of an additional turbine nearby on the outcome variable. The main threat to identification of a causal relationship is posed by endogenous siting of wind turbines, e.g because citizens actively block wind power near their homes. ${ }^{5}$ To address this issue, we exploit spatio-temporal variation in the profitability of wind turbines in an instrumental-variables regression with location fixed effects. Specifically, the cross-sectional differentiation of federal production subsidies according to local wind potential, combined with multiple adjustments to the overall subsidy rates that occurred over time, have been shifting investment incentives for wind turbines in ways that are arguably exogenous to local preference dynamics.

\footnotetext{
${ }^{2}$ Wind contributes 6.1 percent to the Chinese and and 8.4 percent to the U.S. total electricity consumption. See China Energy Portal (2021) and U.S. Energy Information Administration (2021).

${ }^{3}$ See, for instance, Bloomberg, 2019 or Financial Times, 2019.

${ }^{4}$ There are more than 1,000 organized citizens' initiatives against wind turbine projects in Germany, 900 of them in the federal association Vernunftkraft.

${ }^{5}$ Citizens' initiatives and private persons are involved in 62 percent of all law suits filed against wind projects according to the German Wind Energy Association (BWE), 2019. Environmental associations represent another major opponent in many cases.
} 
We find that the construction of new wind turbines has negative and significant effects on both preferences measures. Using data on more than 35 million individual search queries conducted on price comparison websites, we estimate that an additional wind turbine reduces searches for green electricity tariffs in the same postal code by 35 percent. We study search rather than purchase behavior in order to obtain a preference measure that is independent of price differences between renewable and conventional electricity. Such price differences are systematic and drive tariff choices, thus preventing us from disentangling preferences and prices with observational data. ${ }^{6}$ Focusing on tariff searches sidesteps this issue because users of the price comparison website are not given any information on prices prior to entering their search query. Nonetheless, search queries are an accurate predictor of actual tariff choices, as we show in the data section.

Using data on federal elections, we estimate that an additional wind turbine in a municipality significantly reduces the vote share of the Green Party by 17 percent. In elections to the European Parliament, we estimate an even larger reduction of 23 percent, which we attribute to the fact that European elections matter more for protest voters. ${ }^{7}$

Our main finding of a negative treatment effect of wind turbines on tariff searches and vote shares is robust to functional form and corroborated by placebo tests where we randomly assign the WTs to other areas. Analysis of treatment heterogeneity across demographic groups shows that the effect is largest in rural areas and where the economy is sound. Moreover, the magnitude of the treatment effects decreases rapidly when we increase the radius around the wind turbines, suggesting that externalities provoking a NIMBY attitude are very local.

Our findings have important policy implications for countries that, like Germany, "are covered by a contiguous and dense mesh of buildings" (Behnisch et al., 2019). To achieve climate targets under these circumstances, siting new wind turbines closer

${ }^{6}$ For a standard two-person household with 3.5 MWh annual electricity consumption green electricity tariffs are on average 4.6 percent more expensive than regular tariffs in our observation period.

${ }^{7}$ European elections tend to be perceived as "second-order-national-contests" where voters are more willing to express dissatisfaction with a party's national politics (Hix and Marsh, 2007). 
to buildings will be inevitable and exposes a greater population share to negative externalities. This increases the likelihood that a critical mass of opponents to wind power could stop the energy transition via the legislative channel, making it a victim of its own success. Such a "NIMBY equilibrium" is socially undesirable under the premise that renewable energy is globally welfare-improving. To boost citizen support for wind turbines, policy makers could offer financial compensation to affected communities. We provide suggestive evidence that such a strategy could be effective by showing that (i) wind power expansion leads to higher commercial tax revenues at the regional level, and that (ii) the negative effects of wind power on tariff searches and votes are substantially smaller in regions that benefited from higher tax revenues after a change in the local taxation of wind power profits.

Our analysis contributes to a sizable literature estimating the preferences for renewable energy (reviewed in the next section). While most of this literature considers stated-preference measures, revealed-preference studies have thus far been limited to hedonic analysis of housing markets. Our study breaks new ground on this by analyzing preferences revealed in two distinct yet highly relevant markets, namely elections "the market in which votes are exchanged for public-policy outcomes" (Crain, 1977) and the market for renewable electricity. We regard this as an important complement to hedonic studies, which have the benefit of providing monetized welfare impacts of new energy infrastructure, but also rely on the strong assumptions that agents are fully informed and move in frictionless housing markets to establish a new hedonic equilibrium (Rosen, 1974; Roback, 1982). To the extent that moving is costly and agents have less costly alternatives, welfare impacts are not fully capitalized into housing prices. In our particular application, this is plausible because the costs of moving away likely outweighs the disamenity value of wind turbines for most affected residents, and because they have the option of launching litigation against projected wind parks.

The remainder of this paper is structured as follows: Section 2 provides an overview of the related literature and Section 3 presents the institutional background of wind power deployment in Germany. Our empirical strategy is outlined in Section 4 and the 
data are described in Section 5. Section 6 summarizes the empirical results, Section 7 investigates the potential for compensation payments, and Section 8 concludes.

\section{Literature}

A sizable literature seeks to identify the preferences for renewable energy based on both stated and revealed preferences. Two key findings of that literature are that renewable energy is generally preferred to fossil energy sources due to its more environmentallyfriendly production process but also gives rise to local externalities that reduce welfare. In what follows, we summarize this literature and describe this paper's precise contribution to it.

Renewable electricity generation is often more costly than generation from conventional sources and thus commands higher prices. This fact has motivated researchers to estimate the willingness-to-pay (WTP) for green electricity. Meta-analyses based on 227 WTP estimates taken from 47 studies show that households state a positive WTP for green electricity, with differing values across the specific renewable energy technologies (Ma et al., 2015; Sundt and Rehdanz, 2015). WTP estimates are higher for solar and wind electricity than for electricity generated from hydro power and biomass. In addition, WTP is positively related to renewable electricity generation in current energy consumption (Ma et al., 2015). In regards to household characteristics, Ma et al. (2015) find that WTP estimates are negatively associated with electricity consumption. Sundt and Rehdanz (2015) identify individual knowledge about renewable energy technologies, income, and education as important determinants of WTP estimates. However, these studies also highlight uncertainties stemming from the use of different valuation methods. Sundt and Rehdanz (2015) find that choice experiments are associated with higher WTP estimates. Ma et al. (2015) conclude that the characteristics of the study design "explain a large proportion of the variation in WTP values across studies".

Studies on actual decisions to consume green electricity - rather than stated preferences - are much more rare. They reveal that decisions to purchase green electricity 
or to participate in green electricity programs depend on factors such as household characteristics, environmental concerns, and warm glow motives (e.g. Menges et al., 2005; Kotchen and Moore, 2007a; Jacobsen et al., 2012).

When it comes to externalities of renewable energy technologies, there is a host of case studies and qualitative analyses that shed light on public acceptance and document NIMBY attitudes. ${ }^{8}$ Meta studies on the externalities of wind and hydro power using stated preferences methods can be found in Mattmann et al. (2016a) and Mattmann et al. (2016b), respectively. Stated-preferences methods such as contingent valuation offer the benefit of near-universal applicability, but they have also been criticized for giving unreliable results due to hypothetical biases or framing effects (see Hausman, 2012; Kling et al., 2012, for more detailed discussions).

One strand of literature uses self-reported well-being data to quantify the externalities of renewable energy technologies. Krekel and Zerrahn (2017) find negative effects of new wind turbines on reported life satisfaction in Germany. In a comparative analysis of different technologies, von Möllendorff and Welsch (2017) find that well-being externalities associated with biomass are stronger than for wind and solar power.

Revealed-preference estimates of the value of externalities emanating from power plants have been mainly derived in hedonic analyses of housing prices (see, e.g., Davis, 2011; Dastrup et al., 2012; Heintzelman and Tuttle, 2012). These studies have shown that negative external effects from wind turbines and conventional power plants lead to lower property prices in the surrounding areas. Sunak and Madlener (2016) find that asking prices for properties that looked onto newly installed wind turbines in Germany experienced a drop of between 9 and 14 percent. Similarly, Gibbons (2015) and Jarvis (2021) provide evidence from the United Kingdom that wind farm visibility reduced local house prices, leading to substantial environmental costs. Jensen et al. (2014) disentangle the effect of visual pollution and noise pollution of wind turbines in Denmark. They estimate a negative effect on residential property prices of up to 3 percent for the former and between 3 and 7 percent for the latter externality. However,

\footnotetext{
${ }^{8}$ See the meta-analysis by Aitken (2010) for an overview on wind power, or van der Horst (2007), on the "not in my backyard" phenomenon.
} 
while house prices are negatively affected by nearby wind turbines, land owners in windy areas may profit from the capitalization of wind energy subsidies into land prices, as shown by Haan and Simmler (2018).

We contribute to the above literature by bringing revealed-preference data from markets other than real estate markets to bear on this issue. Our analysis of online search queries for renewable electricity tariffs adds a new preference measure for renewable electricity technologies, which is based on the premise that "concern for the environment translates into predictable patterns of consumer behavior" (Kotchen and Moore, 2007b). Our analysis of electoral vote shares for the Green Party speaks to such preferences because this party, after joining the federal government in 1998, paved the way for the rapid diffusion of renewable energy technologies that Germany has seen ever since. This insight has been used previously by Comin and Rode (2015), who relate vote shares for the Green Party to the geographic diffusion of solar photovoltaic systems installations. They estimate that households that install on-roof systems become more supportive of the Green Party. Our study is different not only in terms of the technology studied, but also because we focus on externalities of wind turbines to neighboring households. Another closely related study by Stokes (2016) analyzes the effect of wind turbine deployment in the province of Ontario (Canada) on elections, albeit in a smaller program and over a shorter time horizon. She estimates losses of 4 to 10 percent to the incumbent party's vote share in provincial (but not national) elections.

Both these studies rely on geographic variation in solar radiation intensity (Comin and Rode, 2015) and wind potential (Stokes, 2016), respectively, to instrument for local technology adoption. In contrast, we propose an identification strategy that exploits both cross-sectional and temporal sources of exogenous variation in profitability to instrument for wind turbine deployment. Credible identification is of utmost importance because local preferences for renewables likely influence the patterns of adoption. For example, Jarvis (2021) shows that local resistance to wind power influences turbine locations, which leads to excess costs of 10-25 percent compared to cost-optimal deployment. By breaking the correlation between unobserved shocks to wind turbine 
deployment and the outcome variables, our estimation strategy avoids any bias that could arise due to such reverse causality.

\section{Institutional Background of Wind Power in Germany}

Beginning in the early 2000's, Germany embarked on a period of rapid growth in wind energy. Installed onshore wind power capacity soared from $6.1 \mathrm{GW}$ in 2000 to 26.8 GW in 2010 and 54.4 GW in 2020, respectively. The share of wind energy in gross electricity consumption rose from 1.7 percent in 2000 to 6.2 percent in 2010 and reached 18.7 percent in $2020 .{ }^{9}$ Figure 1 illustrates this development.

Figure 1: Development of wind power capacity and contribution in Germany

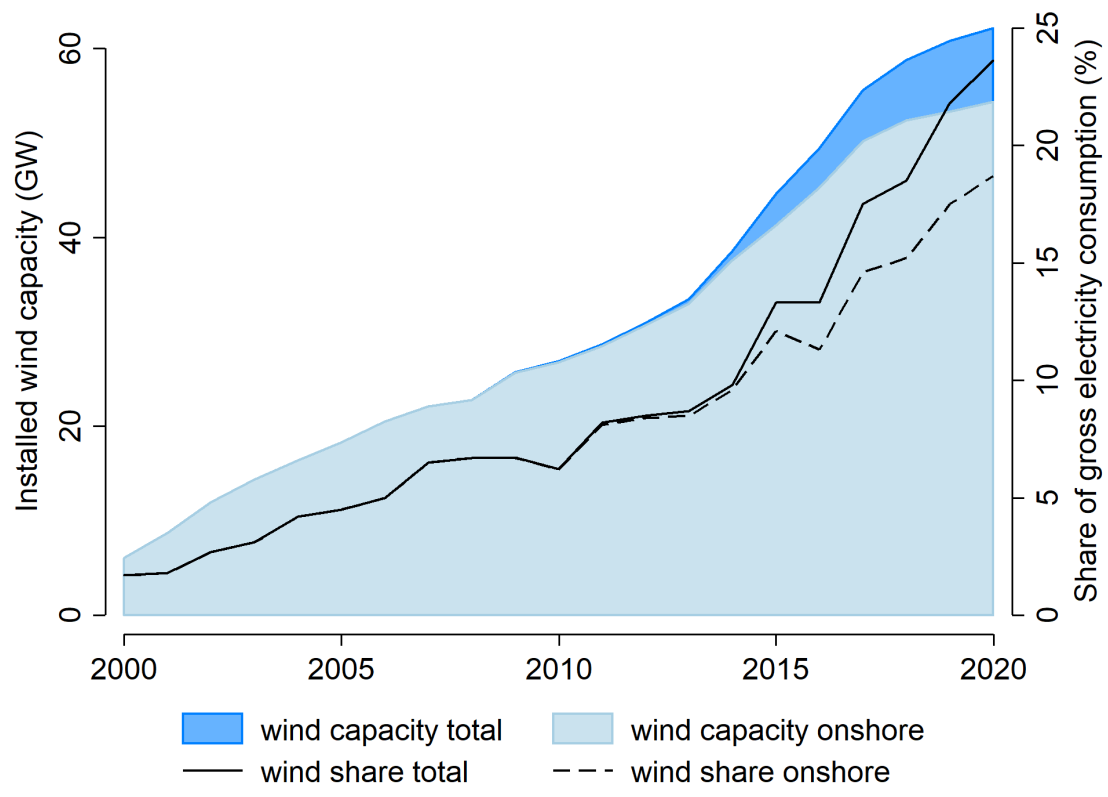

Notes: Calculation based on data from the German Federal Ministry for Economic Affairs and Energy (BMWi, 2020).

Much of this expansion has been attributed to government policies, in particular to subsidization of renewable systems through legislated feed-in tariffs. These tariffs guarantee a fixed price for every kilowatt hour of renewable electricity produced with

${ }^{9}$ The second largest renewable energy source in Germany is solar energy with a share of 9.2 percent of total energy consumption as of 2020 (BMWi, 2020). 
an eligible technology and fed into the grid. In addition, renewable electricity enjoys priority feed into the grid. These privileges were stipulated in the Renewable Energy Sources Act (henceforth referred to by its German acronym, EEG), a federal law enacted in 2000 under the auspices of a government formed by the social democrats and the Green Party (as a first-time junior coalition partner). ${ }^{10}$

Feed-in tariffs are differentiated by technology and size, resulting in different subsidy levels granted for wind, solar photo-voltaic, biomass, and other systems. The tariff levels are administratively determined and regularly adjusted for the installation of new systems based on estimates of their electricity generation cost. ${ }^{11}$ For an individual system, the nominal tariff that is valid at the date of installation remains constant over time and is granted for 20 years.

Feed-in-tariffs to wind turbines are also geographically differentiated according to the so-called reference yield model, which grants higher subsidies per unit of electricity generated in locations with low wind potential. By levelling incentives for wind power generation across space, this scheme seeks to mitigate potential grid constraints and to reduce volatility in aggregate wind power generation. The reference yield model consists of a benchmarking component and a tariff schedule. Locations are benchmarked against a reference location with an expected power output (reference yield) for specific technologies. ${ }^{12}$ Yields at any given location are divided by the reference yield, i.e., the yield computed for a benchmark wind potential stipulated in the EEG law. This yield ratio ranges from 0.3 to 2.2 in our data. The tariff schedule under the reference yield model consists of a high initial tariff paid at the beginning, and a lower base tariff that applies thereafter. The length of the initial period is at least five years, plus an extension that declines with the yield ratio. Thus, a low-yield location is eligible for the higher initial tariff for a longer period than a high-yield

\footnotetext{
${ }^{10}$ The EEG superseded the Electricity Feed-in Law (Stromeinspeisungsgesetz) dating from 1991.

${ }^{11}$ More recently, tendering of support levels has been introduced for large wind and solar systems. However, this market design adjustment took place after the period analyzed in this paper.

${ }^{12}$ More specifically, the wind power potential of the reference location is defined by law based on average annual wind speed of 5.5 meters per second at 30 meters above the ground, a logarithmic elevation profile, and a roughness length of 0.1 meters (i.e., the theoretical height above the ground at which the mean wind speed is zero). The conversion of wind potential into electric power is based on the technical characteristics of a pre-specified reference plant.
} 
location. This is the mechanism that dampens cross-sectional differences in expected profitability of wind turbines.

Table 1: Structure of Feed-In Tariffs at the Time of Enactment

\begin{tabular}{lrrl}
\hline EEG amendments & $\begin{array}{r}\text { Initial tariff } \\
\text { [cts. / kWh] }\end{array}$ & $\begin{array}{r}\text { Base tariff } \\
\text { [cts. / } \mathrm{kWh} \text { ] }\end{array}$ & Extension of initial tariff \\
\hline $\begin{array}{l}\text { EEG 2000 } \\
\text { (effective 04/2000) }\end{array}$ & 9.10 & 6.19 & $\begin{array}{l}2 \text { months per }-0.75 \% \text { deviation from } 150 \% \\
\text { of reference yield }\end{array}$ \\
$\begin{array}{l}\text { EEG 2004 } \\
\text { (effective 08/2004) }\end{array}$ & 8.70 & 5.50 & $\begin{array}{l}2 \text { months per }-0.75 \% \text { deviation from } 150 \% \\
\text { of reference yield }\end{array}$ \\
$\begin{array}{l}\text { EEG 2009 } \\
\text { (effective 01/2009) }\end{array}$ & 9.20 & 5.02 & $\begin{array}{l}2 \text { months per }-0.75 \% \text { deviation from } 150 \% \\
\text { of reference yield }\end{array}$ \\
$\begin{array}{l}\text { EEG 2012 } \\
\text { (effective 01/2012) }\end{array}$ & 8.93 & 4.87 & $\begin{array}{l}2 \text { months per }-0.75 \% \text { deviation from } 150 \% \\
\text { of reference yield }\end{array}$ \\
$\begin{array}{l}\text { EEG 2014 } \\
\text { (effective 08/2014) }\end{array}$ & 8.90 & 4.95 & $\begin{array}{l}2 \text { months per }-0.36 \% \text { deviation from } 130 \% \\
\text { of reference yield }+1 \text { month per }-0.48 \% \\
\text { deviation from } 100 \% \text { of reference yield }\end{array}$ \\
\hline
\end{tabular}

Notes: EEG is the German acronym for the Renewable Energy Sources Act (Gesetz für den Ausbau erneuerbarer Energien).

The identification strategy we propose below exploits the fact that wind power subsidies also varied considerably over time. This is because the EEG law was amended several times between 2000 and 2014, inducing multiple changes in both initial and base tariffs as summarized in Table 1. The 2012 amendment granted feed-in-tariffs also to locations with less than 60 percent of the reference yield, which had previously been excluded from the reference yield scheme. Additional time variation in tariffs derives from annual digressive adjustments that were stipulated in the amendment and applied in the years following its implementation. Figure 2 plots the resulting variation in the initial and base tariffs pertaining to new wind turbines deployed in each year between 2006 and 2014. Tariffs generally decreased over time, but some amendments induced upward jumps. ${ }^{13}$

\footnotetext{
${ }^{13}$ For example, in 2012, the level of the initial and base tariffs were 8.90 and 4.95 euro cents per kWh, respectively. This decreased to 8.66 and 4.72 euro cents per $\mathrm{kWh}$ due to annual digression. With the enactment of the EEG amendment in August 2014, both tariffs increased again to 8.90 and 4.95 cents per $\mathrm{kWh}$, respectively. The increase in the initial tariff in 2009 amendment reflected cost increases in wind turbine installations, in particular increasing resource costs (Böttcher, 2010).
} 
Figure 2: Development of feed-in tariffs for wind, 2006-2014

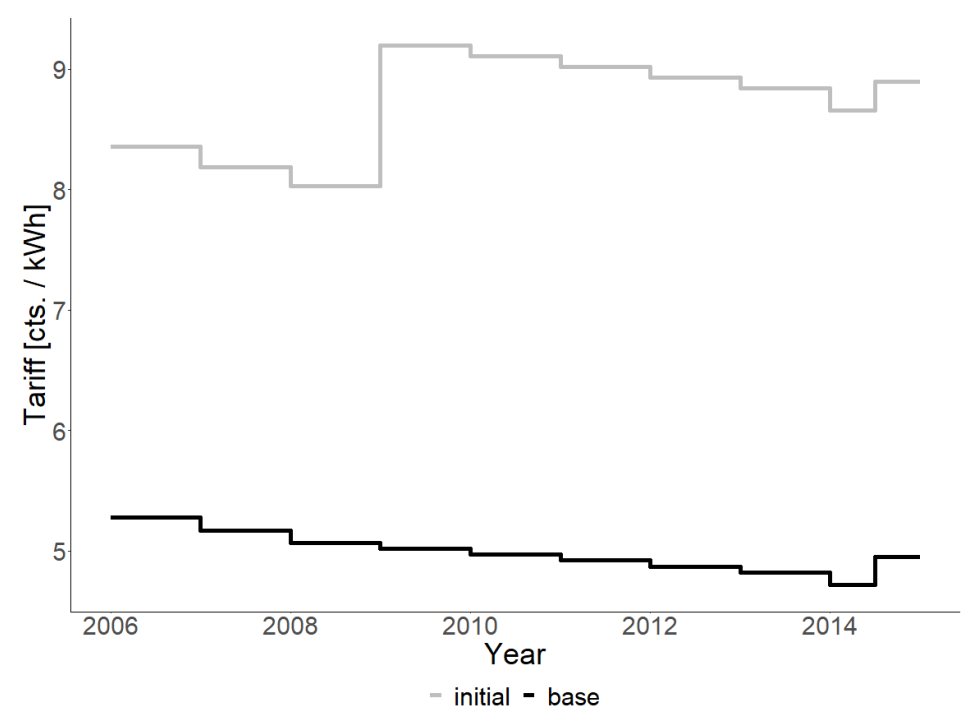

Notes: Own illustration based on data from the German Transmission System Operators (2019).

\section{Research Design}

Our aim is to test whether citizens curb their support for renewable electricity when exposed to local externalities associated with its production. As discussed in Section 2 above, this presents challenges in terms of measurement and identification.

\subsection{Measuring Preferences for Renewable Electricity}

We address the measurement issue by studying two granular indicators of revealed preferences for renewable electricity. One is observed in the corresponding product market, the other one in elections, "the market in which votes are exchanged for publicpolicy outcomes" (Crain, 1977).

The first measure is based on consumer searches on a leading price comparison websites for electricity tariffs. Specifically, we measure the share of search queries with the option "show green electricity tariffs only" checked in the total number of searches. We interpret these consumers as revealing a general preference for renewable energy. In contrast to survey data, which may not reveal true preferences due to cognitive biases, our measure avoids such biases by focusing on observed behavior and actual 
decisions taken by consumers in the pre-contracting stage. In the next section we describe the underlying data and the construction of this measure in detail.

Our second measure is the share of votes received by the Green Party in the German federal elections (Bundestagswahlen). The Green Party was established in 1980 and has been gaining importance in the German political landscape ever since. The party has been represented in the federal parliament (the Bundestag) for the last 25 years. ${ }^{14}$ Between 1998 and 2005, it was part of the first-ever Red-Green federal government coalition partnering with the Social Democratic Party (SPD). The transition of the energy sector from conventional generation towards renewable energy is the ideological basis of the Green Party and has been a central campaign issue in many elections in particular during our sample period. For example, the term "renewable energy" was mentioned 61 times in the party's 2009 election program and 75 times in the 2013 program. The term "energy transition" appeared twice in 2009 and 74 times in 2013. ${ }^{15}$ Wind plants in particular were mentioned 11 and 36 times and references to "climate" appeared 151 and 153 times, respectively (see Bündnis 90/Die Grünen, 2009, 2013). In view of this, vote shares for the Green Party are well-suited for measuring revealed preferences for renewable energy.

\subsection{Identification and Estimation}

For each revealed-preference measure CS of citizens' support for renewable energy, we conduct a regression-based tests of whether it is affected by nearby wind-turbine deployment. We consider the estimation equation

$$
\log \left(C S_{i t}\right)=\beta_{1} \times W T_{i t}+\mathbf{X}_{i t}^{\prime} \times \beta_{2}+\xi_{i}+\xi_{t}+\varepsilon_{i t},
$$

\footnotetext{
${ }^{14} \mathrm{~A}$ party gets seats in the Bundestag if it receives at least 5 percent of all votes.

${ }^{15}$ The 2013 election was the first federal election held after the 2011 nuclear accident in Fukushima (Japan) which triggered Germany's rapid nuclear exit. The gradual phase-out of nuclear energy had been a project of the Red-Green government which was put on hold by Angela Merkel of the ChristianDemocratic Party when taking office in 2005.
} 
where the explanatory variable of interest is WT, the number of wind turbines (or, alternatively, the installed wind power capacity). The vector $\mathbf{X}$ contains time variant local socioeconomic characteristics, such as average purchasing power, unemployment rates, age, and population density. Subscript $i$ indicates zip codes in regressions of search queries and municipalities in regressions of vote shares, with $\xi_{i}$ being the respective location fixed effects. Time $t$ varies at the annual level, $\xi_{t}$ is a set of year effects, and $\varepsilon$ is an error term.

OLS estimation of eq. (1) recovers the causal impact of wind turbines on the outcome variable under the assumption that the deployment of those turbines is strictly exogenous, conditional on controls $X$ as well as on time and location effects. Fixed effects effectively control for unobserved heterogeneity across regions and for aggregate shocks to renewable energy supply. However, local externalities of wind turbines could lead to simultaneity of preferences for renewables and the expansion of wind capacity. Reaching heights of up to 200 meters, wind turbines can have an invasive impact on townscapes and landscapes which threatens to lower the market value of real estate. Consequently, planned wind power projects are frequently met with local opposition, and citizens' initiatives have been successful in blocking many such projects. ${ }^{16}$ If indeed fewer wind turbines are built in areas with weaker support for renewable energy, ignoring this feedback will lead to upward bias in the OLS coefficient on WT in eq. (1).

To address this issue, we adopt an instrumental-variable (IV) approach based on quasi-experimental variation in the profitability of wind energy. As explained in Section 3 above, the feed-in tariff scheme of the German reference yield model induces variation in expected revenues for wind power across locations and over time. To be a valid instrumental variable, changes in expected revenues must be (i) correlated with local trends in wind power deployment, and (ii) unrelated to unobserved local shocks that confound the impact of wind-turbine deployment on the outcome variable.

Assumption (i) that expected revenues are relevant for wind-turbine installation is plausible because higher revenues increase profitability of and incentives for wind-

\footnotetext{
${ }^{16}$ Further, the effect of an initial blocking of wind projects tends to persist over time (Rode, 2014).
} 
power investments. Moreover, this is a testable assumption. Hitaj and Löschel (2019) present evidence that feed-in-tariffs according to the reference yield model have been driving the installation of wind turbines in Germany. In our sample, we confirm that expected revenues are positively correlated with the number of newly installed wind turbines, as depicted in Figure 3.

Figure 3: Expected Revenues and New Wind Turbine Installations

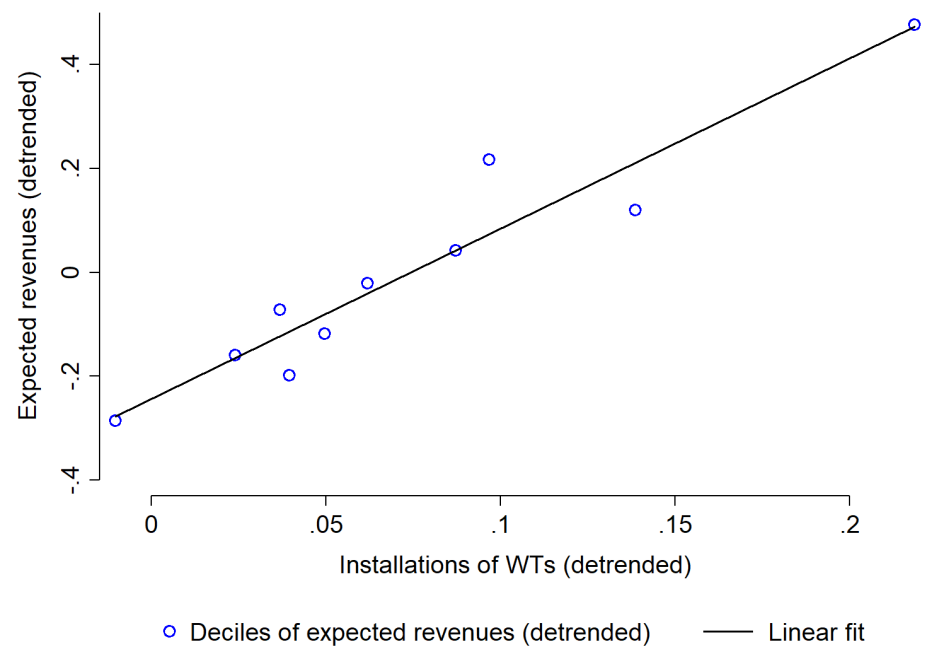

Notes: The figure plots expected revenues from the reference yield scheme against the number of newly installed wind turbines, after residualizing both variables with respect to year dummies. This procedure corrects for both cost reductions in wind turbine construction and reductions in the feed-in tariffs over time.

The exclusion restriction (ii) is not testable and must be assessed on the grounds of plausibility. The revenue of a wind power plant is given by the product of its electric output and its feed-in-tariff. Since output depends on wind availability and strength, locations with high wind power potential generate and sell more electricity than those with low potential. Figure 4a depicts the spatial distribution of normalized wind power potential in Germany, which exhibits stark differences across locations. Feed-in tariffs according to the reference yield model are designed to mitigate the impact of such differences on revenues and enhance the profitability of wind energy investments in less favorable locations. ${ }^{17}$ In Figure $4 b$, we plot the spatial distribution of expected

\footnotetext{
${ }^{17}$ As explained in Section 3, locations with a lower potential receive the higher initial tariff for a longer time period than locations with a higher potential. Thus, locations with a lower potential obtain a higher average feed-in tariff for wind turbines over their lifetime.
} 
revenues for wind turbines erected in the year 2013, computed as the product of feed-in tariff and expected output (the representative reference yield), averaged over 20 years, at a specific location. Comparing Figure $4 \mathrm{~b}$ to Figure $4 \mathrm{a}$ reveals that the reference yield model dampens the impact of wind potential on expected revenues, albeit not to the point of equalizing revenues across locations.

Key to our IV strategy are the adjustments to the reference-yield model that were made over time - be it to feed-in tariffs directly or to the set of eligible locations as depicted in Figure 4c. Those adjustments were not targeted at any one location in particular and yet they introduced variation in expected revenues across locations (EEG, 2004, 2009). ${ }^{18}$ When exploiting this variation in our IV model, we rely on highly granular location fixed effects to control for unobserved heterogeneity. Hence, our identifying assumption is that within-location variation in expected revenues is exogenous to contemporaneous shocks in wind-turbine deployment, after conditioning on time-varying covariates.

The first-stage equation thus takes the form

$$
\begin{aligned}
W T_{i t}= & \gamma_{1} \times E_{i t}+\gamma_{2} \times I N E L I G I B L E_{i t}+\gamma_{3} \times I N E L I G I B L E_{i t} \times \text { POTENTIAL }_{i}+ \\
& \mathbf{x}_{i t}^{\prime} \times \gamma_{3}+\xi_{i}+\xi_{t}+v_{i t},
\end{aligned}
$$

where the instrument $E R_{i, t}$ is the expected revenue of a wind turbine built in location $i$ and year $t$ according to the reference yield model. As was mentioned in Section 3, locations with less than 60 percent of the wind potential at the reference location were ineligible for the reference yield scheme before 2012. In this case $E R_{i, t}$ is set to zero. We include INELIGIBLE and INELIGIBLE $\times$ POTENTIAL to capture differences in investment incentives in such occasions. These additional instrumental variables indicate whether a zip code or municipality is ineligible for the reference yield scheme and how large the corresponding wind potential, reflecting heterogeneous investment

\footnotetext{
${ }^{18}$ While the tariff schedule with initial and base tariff and the longer payment of the higher initial tariff for less wind-rich locations are designed to benefit those locations, the adjustments of rates over time are not targeted at specific locations. Rather, adjustments were designed to match the overall cost development and to incentivize further technological improvements and cost-cutting measures in the wind industry.
} 


\section{Figure 4: Wind Power Potential and Reference Yield Remuneration}

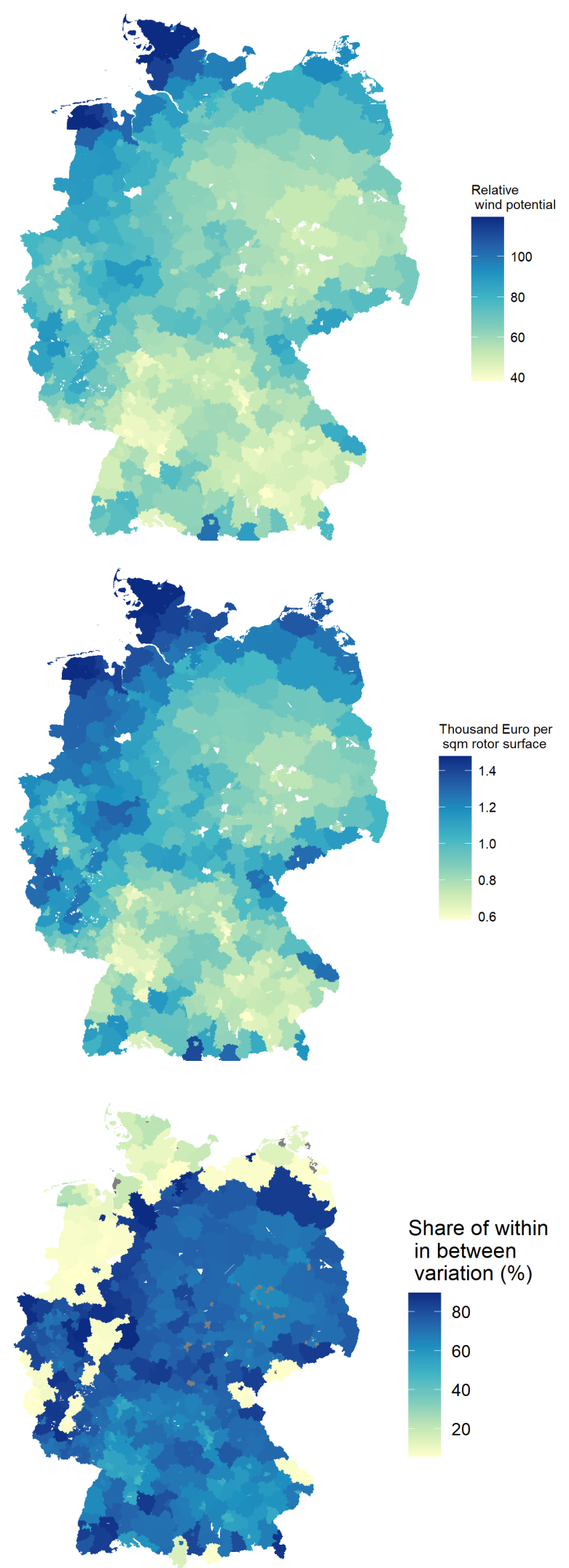

\section{(a) Wind power potential}

Notes: The figure plots the estimated wind power output relative to the reference output. The spatial distribution of wind power potential is very uneven.

\section{(b) Expected revenues}

Notes: The figure shows expected revenues in 2013 based on wind potential and remuneration according to the reference yield model. The reference yield model levels some of the expected revenues over twenty years across regions, but expected revenues remain higher in regions with higher wind potential. To facilitate a visual comparison of the spatial dispersion in profitability before and after subsidies, the color coding in Figures $4 \mathrm{a}$ and $4 \mathrm{~b}$ is based on quantiles of the distributions of wind power potential and expected revenues, respectively.

\section{(c) Within variation in expected revenues}

Notes: The adjustments in feed-in tariffs lead to changes in expected revenues. The figure shows the within variation of expected revenues relative to its between variation measured both by their standard deviations. We exclude expected revenues with zero for regions that were ineligible due to their low wind potential before 2012. The figure shows sizeable within variation for the different regions. 
incentives in ineligible locations. More details on the construction of the instruments are given in the next section. Notation for the other explanatory variables is the same as above.

\section{Data}

\subsection{Data Sources}

Our data stem from several sources. We obtained detailed data on search queries for electricity tariffs from ene't, a German software and data provider for the electricity industry, who operates several price comparison websites. Data on election outcomes were gathered from the German Federal Statistical Office. energymap provided the data on renewable energy plants. The German Meteorological Service (Deutscher Wetterdienst, DWD) provided us with data on local wind intensity, while data on local feed-in tariffs for wind turbines were collected from netztransparenz.de. Finally, the marketing company Acxiom provided data on socioeconomic and demographic characteristics in Germany at the zip code level, while we collected similar variables at the municipality level from the German Federal Office for Building and Regional Planning and the German Federal Statistical Office.

The spatial data resolution is at the German zip code level (8,039 zip codes) for the green electricity tariff queries and at the municipality level $(10,003)$ for the election outcomes. For the green electricity tariff queries, we analyze the period 2011 to 2014 . This period was chosen because earlier data were not available, and because the remuneration scheme for wind power was subject to a major change after 2014. ${ }^{19}$ During this period, the installed net capacity from wind energy experienced a substantial expansion, rising from $26.9 \mathrm{MW}$ by the end of 2010 to $38.6 \mathrm{MW}$ by the end of 2014 - a total increase of 43 percent in only four years. In our analysis of Green Party votes, we use data from the Bundestag elections in 2009 and 2013. The installed net wind capacity

\footnotetext{
${ }^{19}$ The 2014 amendment of the EEG law required large wind turbines that started operating after 2014 to sell their electricity competitively in the spot market. Instead of a feed-in-tariffs, those plants only received an additional market premium for green electricity, which weakens our instrument.
} 
increased from 22.8 MW at the end of 2008 to $33.5 \mathrm{MW}$ by the end of 2013 - a total increase of 47 percent in only four years.

In what follows, we describe how we construct the outcome variables from the raw data and subsequently provide information on control variables. Descriptive statistics for both datasets are summarized in Tables 2 and 3 below.

\subsection{Outcome Variables}

Search queries for green electricity tariffs. In 1999, Germany liberalized electricity markets by allowing entry to local markets and allowing consumers to freely choose between different electricity retailers and tariffs. This brought about the end of local monopolies as many electricity retailers have entered the market since. ${ }^{20}$ A large majority of households use price comparison websites to compare electricity tariffs and switch suppliers. ${ }^{21}$.

We observe all tariff queries conducted between March 2011 and December 2014 on several well-known online price comparison platforms for electricity tariffs including Toptarif.de (top tariff), Stromtipp.de (power tip), Energieverbraucherportal.de (energy consumption portal) and mut-zum-wechseln.de (courage-to-change), of which Toptarif.de is by far the biggest platform. A screenshot of Toptarif's interface is shown in Figure 5 .

\footnotetext{
${ }^{20}$ In our observation period there were on average 133 electricity retailers per zip code offering their services (with a range of 55 to 192).

${ }^{21}$ This was already the case at the beginning of our observation period. According to an early study 80 percent of switchers already used price comparison websites in 2011. See AT Kearney, 2011.
} 


\section{Figure 5: Screenshot of the Price Comparison Website "Toptarif"}

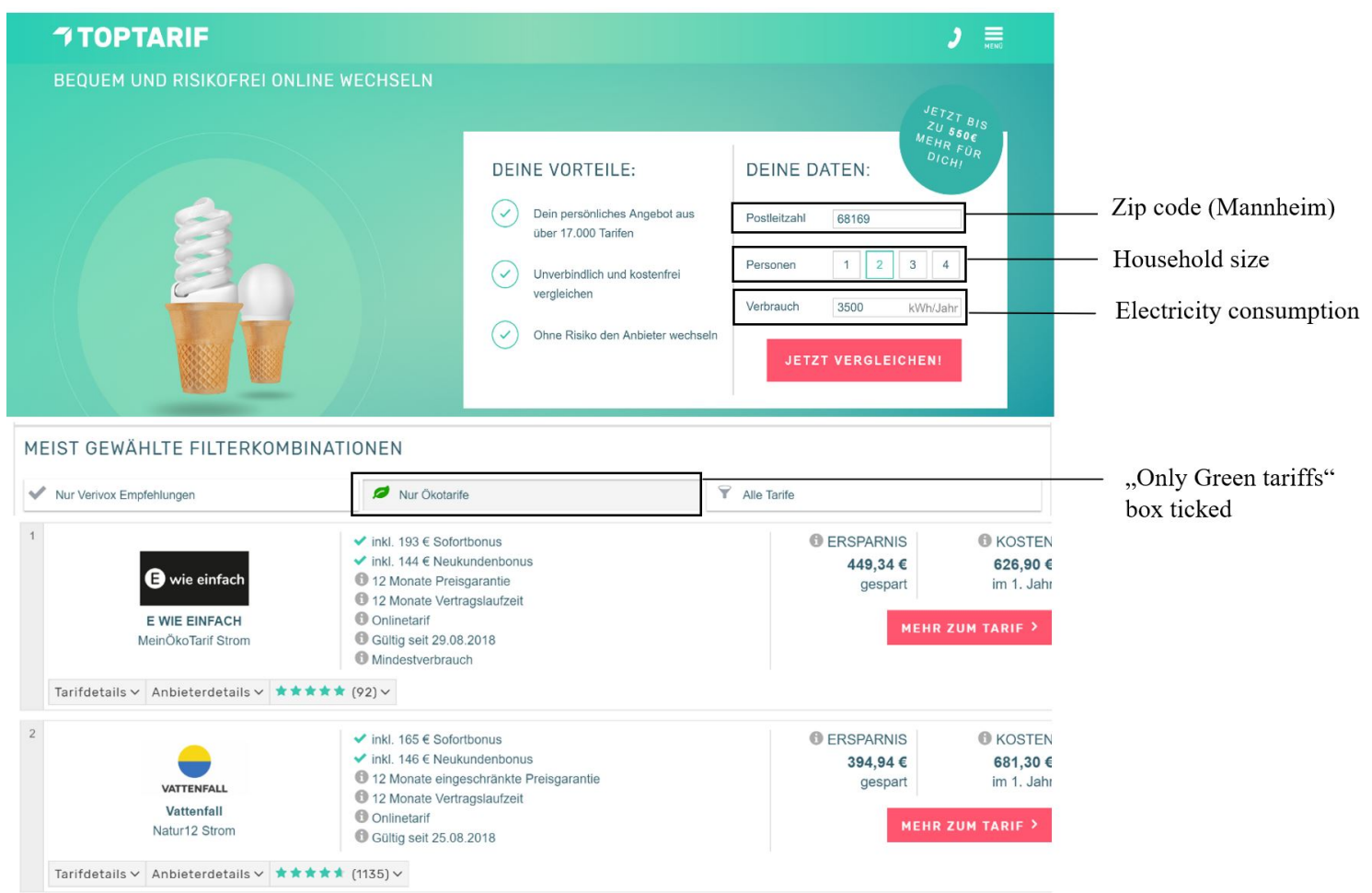

For each search query we observe the timestamp, the zip code for which information on local electricity tariffs is requested, the (expected) annual consumption entered into the search interface, the type of search query (household or industrial customer), a search session ID indicating the order of the queries of each searching consumer as well as the options ticked by the consumers. These options allow to refine the search query according to the consumer's personal preferences, and to compare results obtained when ticking different options. For instance, consumers can choose whether or not the ranked tariffs include package tariffs or switching premiums, and whether to only compare tariffs with price guarantees etc. Of utmost importance for our analysis is whether a searcher ticked the box "show green tariffs only" as this speaks to the consumer's preference for renewable energy.

In sum, we have information on $35,855,071$ search queries from $17,302,530$ search sessions of which 96.7 percent (i.e. 16,778,214 sessions) were conducted by households and the remaining 3.3 percent (i.e. 524,316 sessions) by industrial customers. In our analysis, we focus on households and therefore exclude search queries from commercial users. We aggregate the data to the zip code-year level. The yearly aggregation 
is equivalent to the assumption that each household considers switching the supplier once a year (if at all) which coincides with the typical length of an electricity contract.

We construct a measure of renewable energy support as the ratio of the number of search sessions with the "show green tariffs only" box ticked and the overall number of search sessions in zip code $i$ in year $t$.

Search queries for green electricity tariffs $s_{i, t}=\frac{\text { number of search sessions with box } \text { ticked }_{i, t}}{\text { number of search sessions } s_{i, t}}$,

We compute the following three such measures:

(i) First query: The number of search sessions where the "show only green tariffs" option is ticked already for the first query of a consumer's search session. Consumers who immediately search for green tariffs are likely to have a very strong preference for green tariffs. This is our preferred measure as it plausibly carries the cleanest signal of a preference for green electricity.

(ii) Any query: The number of search sessions where the "show only green tariffs" option is ticked in at least one query of a search session. If a consumer ticks this option at least once in a search session, we assume a generally positive attitude towards green energy.

(iii) Last query: The number of search sessions where the "show only green tariffs" option is ticked in the last query. The appeal of this measure is that, of all three measures, it likely exhibits the strongest correlation with a consumer's final choice. The downside is that, at this point of the search, the consumer may already be informed about the price premium associated with green electricity tariffs.

The share of households with preferences for green tariffs is rather low as can be seen in Table 2. Only six percent of all searching households ticked the "show only green electricity tariffs" box at least once in a search session. The percentage of households that already ticked the box for their first query is around 3.7 percent of 
all searching households. These households can be regarded as having the highest preference for renewable energy. On average, 2.1 wind turbines are installed in a zip code, 3 wind turbines within a radius of $5 \mathrm{~km}$ from the zip code's center, and 10.4 wind turbines within $10 \mathrm{~km}$ from the center. The regional distribution of the share of green tariff queries for 2013 is shown in Figure 7a.

We focus on consumer search activity, but not actual contracting decisions. These two can be separated because the search yields a price comparison where clicking on a specific supplier's tariff redirects the user to a website where the switch can be finalized. If we used green electricity contracts as the outcome variable, this would be a truncated measure of preferences for green electricity, because consumers whose valuation of green electricity is smaller than the (minimum) price difference between regular and green electricity will not choose a green tariff. In contrast, tariff searches capture preferences for green electricity but circumvent the problem of prices affecting choices. ${ }^{22}$

Last not least, search activity is highly relevant because it strongly predicts consumers' contracting decisions. When we compare the number of search sessions from the ene't data with data on actual switching of electricity suppliers from Verivox - another major price comparison site for electricity tariffs - we find that the two variables are strongly and positively correlated, as shown in Figure 6.

\footnotetext{
${ }^{22}$ Our measure would miss consumers with positive-yet-small valuation of green electricity if they refrain from searching such tariffs in anticipation of high price premia. We do not deem this a very likely scenario.
} 
Figure 6: Electricity Tariff Searches and Contract Switches Over Time

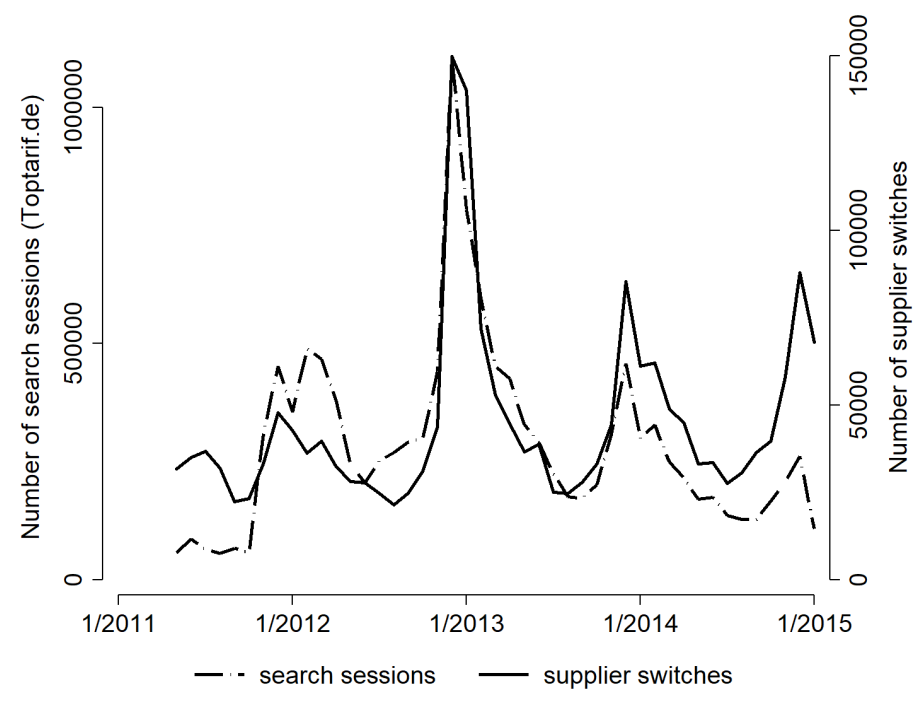

Green Party votes. Data on the election outcomes at the municipality level for the 2009 and 2013 Bundestagswahl come from the German Federal Statistical Office. On average the Green Party received 8.6 percent of votes per municipality in 2009 and 6.5 percent in 2013. The spatial distribution of vote shares for the 2013 Bundestagswahl is displayed in Figure $7 \mathrm{~b}$.

Figure 7: Spatial Distribution of Outcome Variables in 2013

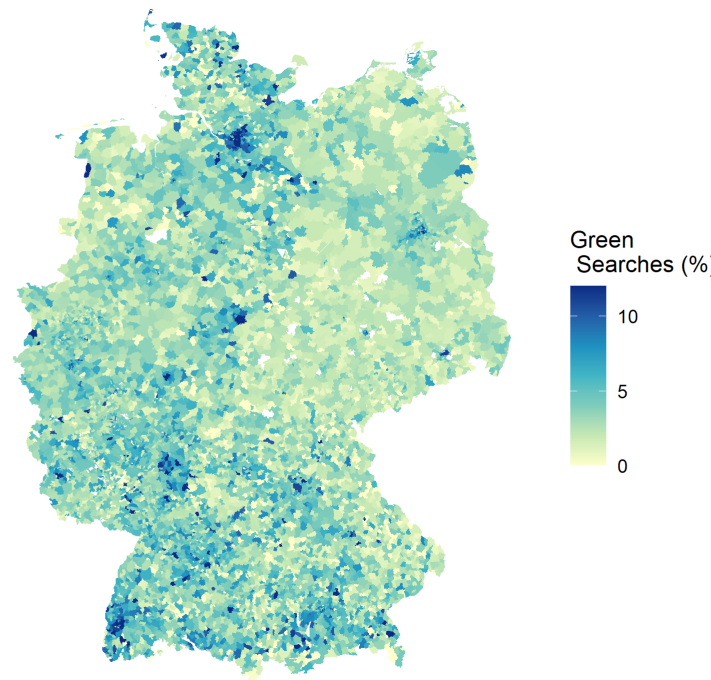

(a) Green searches share

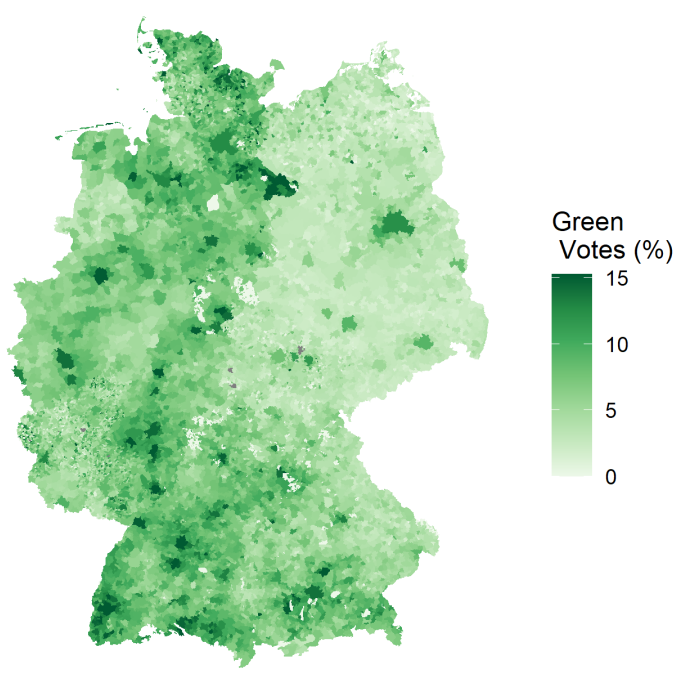

(b) Green Party vote share 


\subsection{Explanatory Variables}

Wind turbines. The energymap project (energymap.de) provides detailed information on renewable energy plants including the plant type (e.g. wind, solar, hydro etc.), net capacity, geo-coordinates and the date of commissioning. The dataset is based on the official plant installation register of the German Transmission System Operators (TSO). We use this dataset to construct our variables of interest, i.e. the number and capacity of the WTs in a certain zip code or municipality and within a radius of $1 \mathrm{~km}$, $3 \mathrm{~km}, 5 \mathrm{~km}, 7 \mathrm{~km}, 10 \mathrm{~km}$ and $20 \mathrm{~km}$ from the centroid of the zip code or municipality. Figure 8 shows the spatial distribution of the stock of wind turbines in Germany for the year 2013. While it is immediately seen that more turbines are installed in the northern half of the country, it is also clear that the distribution is not a mirror image of that of wind power potential (see Figure 4a). That is, factors other than potential output have shaped the distribution of wind turbines in space.

Feed-in Tariffs and Socio-Economic Data. We calculate the expected revenue of each wind turbine based on the reference yield model, using data on local wind potential from the German Meteorological Office (Deutscher Wetterdienst - DWD), as well as information on initial and base tariffs obtained from the German Transmission System Operators. ${ }^{23}$ Expected revenue during the 20 years of subsidization is given by

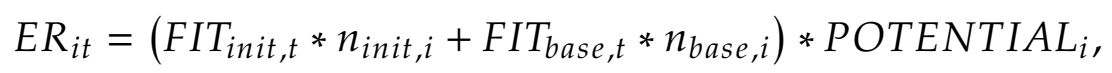

where $F I T_{\text {init,t }}$ and $F I T_{\text {base,t }}$ are the initial and base tariff valid in year $t$, respectively. The terms $n_{\text {init }, i}$ and $n_{\text {base }, i}$ refer to the initial and base period in location $i$, respectively, with $n_{\text {init }, i}+n_{\text {base }, i}=20$ years. ${ }^{24}$ Annual wind potential is denoted by POTENTIAL $i$. The expected revenue is measured in euro cents per square meter of rotor surface over the same time frame. Before 2012, locations with less than 60 percent of the reference yield were ineligible for remuneration according to the reference yield scheme. In

\footnotetext{
${ }^{23}$ See https:/ / www.netztransparenz.de/EEG/Verguetungs-und-Umlagekategorien

${ }^{24}$ See Table 1 for details on the computation of $n_{\text {init }, i}$ and $n_{\text {base }, i}$.
} 


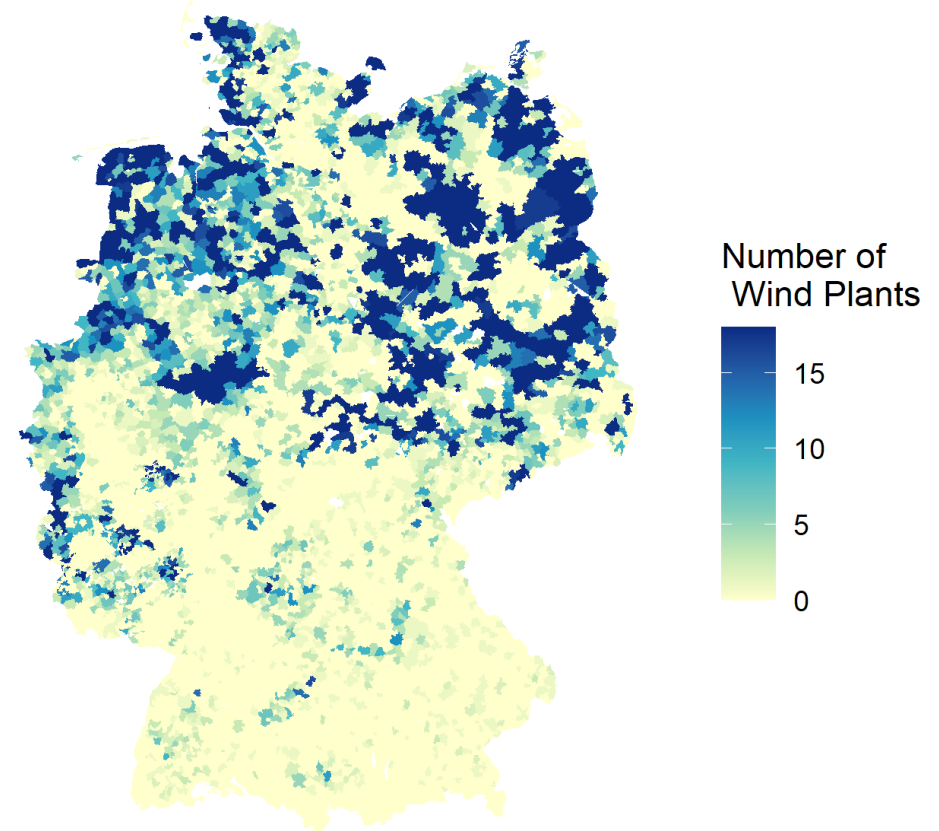

this case $E R_{i t}$ is set to zero, the variable INELIGIBLE is set to one and the variable INELIGIBLE $E_{i t} \times$ POTENTIAL $_{i}$ is set to equal the reference yield. This captures heterogeneous investment incentives in such ineligible locations.

Furthermore, we use socio-economic and demographic data to control for timevarying local changes, e.g., purchasing power, unemployment, population and household age. These data are obtained from Acxiom for the zip code level and from INKAR and the German Federal Statistical Office for the municipality level. Data on commercial taxes of municipalities stem from the German Federal Statistical Office. 
Table 2: Summary Statistics for the Green Tariff Searches Sample

\begin{tabular}{lrrrr}
\hline & Mean & SD & Min & Max \\
\hline Dependent variables & & & & \\
$\quad$ Share of search queries for green tariffs in any query (\%) & 6.30 & 6.17 & 0.00 & 100.00 \\
$\quad$ Share of search queries for green tariffs in first query (\%) & 3.65 & 5.40 & 0.00 & 100.00 \\
$\quad$ Share of search queries for green tariffs in last query (\%) & 5.06 & 5.51 & 0.00 & 96.10 \\
Variables of interest & & & & \\
$\quad$ No. WT within zip code & 2.03 & 5.96 & 0.00 & 102.00 \\
$\quad$ Cap. WT within zip code & 2.79 & 8.49 & 0.00 & 69.32 \\
Instrument and control variables & & & & \\
$\quad$ Expected revenue of a WT (in thousand $€ / \mathrm{m}^{2}$ rotor surface) & 0.90 & 0.30 & 0.20 & 2.30 \\
$\quad$ Purchasing power (in thousands $€ /$ year) & 43.49 & 7.51 & 21.03 & 110.34 \\
$\quad$ Population (in thousands) & 9.95 & 9.09 & 0.00 & 61.99 \\
$\quad$ Young HH (\%) & 24.58 & 5.04 & 0.00 & 55.05 \\
\hline Obs. & 32,252 & & & \\
\hline
\end{tabular}

Notes: Descriptive statistics for zip-code level data. Annual data from 2011 until 2014.

Table 3: Summary Statistics for the Green Party Votes Sample

\begin{tabular}{lrrrr}
\hline & Mean & SD & Min & Max \\
\hline Dependent variables & & & & \\
$\quad$ Share of votes for the Green party in federal elections (\%) & 7.38 & 3.78 & 0.00 & 45.83 \\
$\quad$ Variables of interest & & & & \\
$\quad$ No. WT within municipality & 1.39 & 4.33 & 0.00 & 86.00 \\
$\quad$ Cap. WT within municipality & 1.83 & 5.92 & 0.00 & 49.60 \\
$\quad$ & & & & \\
Instrument and control variables & 1.11 & 0.24 & 0.43 & 2.37 \\
$\quad$ Expected revenue of a WT (in thousand $€ / \mathrm{m}^{2}$ rotor surface) & 10.86 & 18.25 & 0.00 & 100.00 \\
$\quad$ Unemployment (\%) & 6.62 & 28.86 & 0.00 & 1407.84 \\
$\quad$ Population (in thousands) & 69.22 & 14.03 & 0.00 & 185.00 \\
$\quad$ Young HH (\%) & 22,089 & & & \\
\hline Obs.
\end{tabular}

Notes: Descriptive statistics for municipality-level data. Annual data for 2009 and 2013.

\section{Results}

\subsection{Wind Turbines and Preferences for Green Electricity Tariffs}

Table 4 reports the estimated effects of wind turbines (WTs) on the share of households searching for green electricity tariffs, for each of the three definitions given above. Estimation is by 2SLS using the two instruments defined in eq. (4) above. At the bottom of the table we report the first-stage F-statistic for the relevance of the instruments. As the Stock-Yogo 10 percent critical value is 9.08 , our instruments appear to be sufficiently strong to identify local wind power expansion. Also, correcting for endogeneity ap- 
pears to be in order as the Durbin-Wu-Hausman test clearly rejects exogeneity of $W T$. Full first-stage results are reported in Appendix Table A1.

Table 4: Effect of Wind Turbines on Green Electricity Searches

\begin{tabular}{lccc}
\hline & $(1)$ & $(2)$ & $(3)$ \\
& $\log ($ first query) & $\log ($ any query) & $\log ($ last query) \\
\hline No. WT within zip code & $-0.436^{* * *}$ & $-0.458^{* * *}$ & $-0.364^{* * *}$ \\
& $(0.108)$ & $(0.100)$ & $(0.103)$ \\
Population & $0.040^{*}$ & 0.026 & $0.049^{* * *}$ \\
Young HH & $(0.021)$ & $(0.018)$ & $(0.019)$ \\
& -0.012 & -0.007 & -0.013 \\
Purchasing power & $(0.010)$ & $(0.009)$ & $(0.009)$ \\
& $0.012^{*}$ & -0.001 & 0.001 \\
Year FE & $(0.007)$ & $(0.007)$ & $(0.007)$ \\
Zip code FE & Yes & Yes & Yes \\
Durbin-Wu-Hausman test & Yes & Yes & Yes \\
First stage F stat. & 0.00 & 0.00 & 0.00 \\
Obs. & 71.80 & 71.80 & 71.80 \\
\hline
\end{tabular}

Notes: Standard errors clustered at the zip code level in parenthesis. Estimation by 2SLS. Construction of wind turbines is considered endogenous. Instruments based on expected revenues of a wind turbine according to the reference yield model. The period under investigation covers the years 2011 to 2014 . ${ }^{* * *} p<1 \%$, ${ }^{* *} p<5 \%,{ }^{*} p<10 \%$.

In all specifications, the proximity to wind turbines significantly reduces local preferences for green tariffs. An additional wind turbine (WT) reduces the preference for green tariffs by approximately 35 percent ${ }^{25}$ according to the "first query" measure, with very similar results for the alternative measures. ${ }^{26}$

Appendix Table A3 reports results from an alternative specification where we additionally control for local variation in land prices and electricity costs. The rationale for including those variables is that they are correlated with wind power diffusion and may directly affect preferences for green tariffs. ${ }^{27}$ However, since we lack credible

${ }^{26}$ For reference, we provide OLS results in Appendix Table A2. Signs and significance are as in the IV estimations but the magnitudes are substantially smaller, suggesting that neglecting endogeneity leads to an underestimation of the impact of wind turbines on green tariff queries.

${ }^{27}$ For instance, wind turbines exert downward pressure on land prices because of negative externalities for residents, or upward pressure because renewable energy subsidies are capitalized into land prices (Haan and Simmler, 2018). Moreover, an increase in renewable energy capacity subject increases the electricity price both globally (as all consumers have to pay a higher levy to fund the feed-in-tariff scheme) and locally (because wind turbines raise costs for the local grid operator, leading to higher local grid charges).
} 
instruments for these variables, their inclusion may lead to a 'bad controls' problem. Despite such concerns, our coefficient estimate on WT finding remains robust to this exercise. We regard this as suggestive evidence to corroborate our exclusion restriction.

As the dependent variable is non-negative, ${ }^{28}$ we also employ a Poisson Pseudo Maximum Likelihood (PPML) estimator in a robustness check. In these specifications, we estimate the first stage as before and plug the residuals into the PPML model as a control function for endogeneity. The results, reported in Appendix Table A4, are very similar to those from the linear 2SLS regressions.

Since negative externalities of wind turbines are local, their magnitude decays with distance. Consequently, the impact on citizens' support should be strongest in the immediate vicinity of the turbine. To test this hypothesis, we estimate eq. (1) for different threshold distances between WTs and affected citizen. For each zip code, we compute the number of WTs within a circle around the center. The average size of a zip code is $46 \mathrm{~km}^{2}$ and can be approximated by a circle with radius $3.8 \mathrm{~km}$. Table 5 reports estimated treatment effects of WTs for circles with radii between $1 \mathrm{~km}$ and 20 $\mathrm{km}$ and Figure 9 plots the effects of $1 \mathrm{~km}$ increments transformed into percentage. . The estimates clearly show that an additional WT reduces preferences for green tariffs in a zip code by more the closer it is located to the centroid, and that the effect decreases rapidly with distance. A WT less than $1 \mathrm{~km}$ from a zip code's center reduces queries for green tariffs by as much as 86 percent, while the decrease drops to only 2 percent for $20 \mathrm{~km}$, rendering it economically insignificant. ${ }^{29}$ These numbers refer to our preferred search measure where consumers tick the "show only green tariffs" option already in their first query. Again, the results for the other definitions are very similar.

${ }^{28}$ The $\log$ transformation is done by $\log (\mathrm{y}+0.1)$.

${ }^{29} e^{-1.976}-1$ and $e^{-0.024}-1$. 
Table 5: Effect of Wind Turbines on Green Electricity Searches: Distance

\begin{tabular}{|c|c|c|c|c|c|c|}
\hline & \multicolumn{6}{|c|}{ Dependen variable is $\log$ (first query) } \\
\hline & (1) & $(2)$ & (3) & $(4)$ & (5) & (6) \\
\hline No. WT within $1 \mathrm{~km}$ & $\begin{array}{c}-1.901^{* * *} \\
(0.503)\end{array}$ & & & & & \\
\hline No. WT within $2 \mathrm{~km}$ & & $\begin{array}{c}-0.843^{* * *} \\
(0.219)\end{array}$ & & & & \\
\hline No. WT within $3 \mathrm{~km}$ & & & $\begin{array}{c}-0.649^{* * *} \\
(0.156)\end{array}$ & & & \\
\hline No. WT within $5 \mathrm{~km}$ & & & & $\begin{array}{c}-0.327^{* * *} \\
(0.076)\end{array}$ & & \\
\hline No. WT within $10 \mathrm{~km}$ & & & & & $\begin{array}{c}-0.066^{* * *} \\
(0.016)\end{array}$ & \\
\hline No. WT within $20 \mathrm{~km}$ & & & & & & $\begin{array}{c}-0.017^{* * *} \\
(0.004)\end{array}$ \\
\hline Population & $\begin{array}{c}0.062^{* * *} \\
(0.021)\end{array}$ & $\begin{array}{l}0.047^{* *} \\
(0.021)\end{array}$ & $\begin{array}{l}0.051^{* *} \\
(0.021)\end{array}$ & $\begin{array}{c}0.058^{* * *} \\
(0.020)\end{array}$ & $\begin{array}{c}0.074^{* * *} \\
(0.018)\end{array}$ & $\begin{array}{c}0.069^{* * *} \\
(0.018)\end{array}$ \\
\hline Young $\mathrm{HH}$ & $\begin{array}{l}-0.004 \\
(0.011)\end{array}$ & $\begin{array}{l}-0.011 \\
(0.010)\end{array}$ & $\begin{array}{l}-0.008 \\
(0.010)\end{array}$ & $\begin{array}{l}-0.014 \\
(0.010)\end{array}$ & $\begin{array}{l}-0.018^{*} \\
(0.010)\end{array}$ & $\begin{array}{l}-0.017^{*} \\
(0.010)\end{array}$ \\
\hline Purchasing power & $\begin{array}{c}0.005 \\
(0.009)\end{array}$ & $\begin{array}{c}0.008 \\
(0.008)\end{array}$ & $\begin{array}{c}0.009 \\
(0.008)\end{array}$ & $\begin{array}{l}0.015^{* *} \\
(0.008)\end{array}$ & $\begin{array}{l}0.014^{* *} \\
(0.007)\end{array}$ & $\begin{array}{l}0.014^{*} \\
(0.007)\end{array}$ \\
\hline Year FE & Yes & Yes & Yes & Yes & Yes & Yes \\
\hline Zip code FE & Yes & Yes & Yes & Yes & Yes & Yes \\
\hline Durbin-Wu-Hausman test & 0.00 & 0.00 & 0.00 & 0.00 & 0.00 & 0.00 \\
\hline First stage F stat. & 20.15 & 36.02 & 45.90 & 67.62 & 154.69 & 244.76 \\
\hline Obs. & 32,252 & 32,252 & 32,252 & 32,252 & 32,252 & 32,252 \\
\hline
\end{tabular}

Notes: Standard errors clustered at the zip code level in parenthesis. Estimation by 2SLS. The local adoption rate of wind power is considered endogenous. Instruments based on expected revenues of a WT according to the reference yield model. The period under investigation covers the years 2011 to $2014 .{ }^{* * *} p<1 \%,{ }^{* *} p<5 \%,{ }^{*} p<10 \%$.

\section{Figure 9: Effect of Wind Turbines on Green Electricity Searches: Distance}

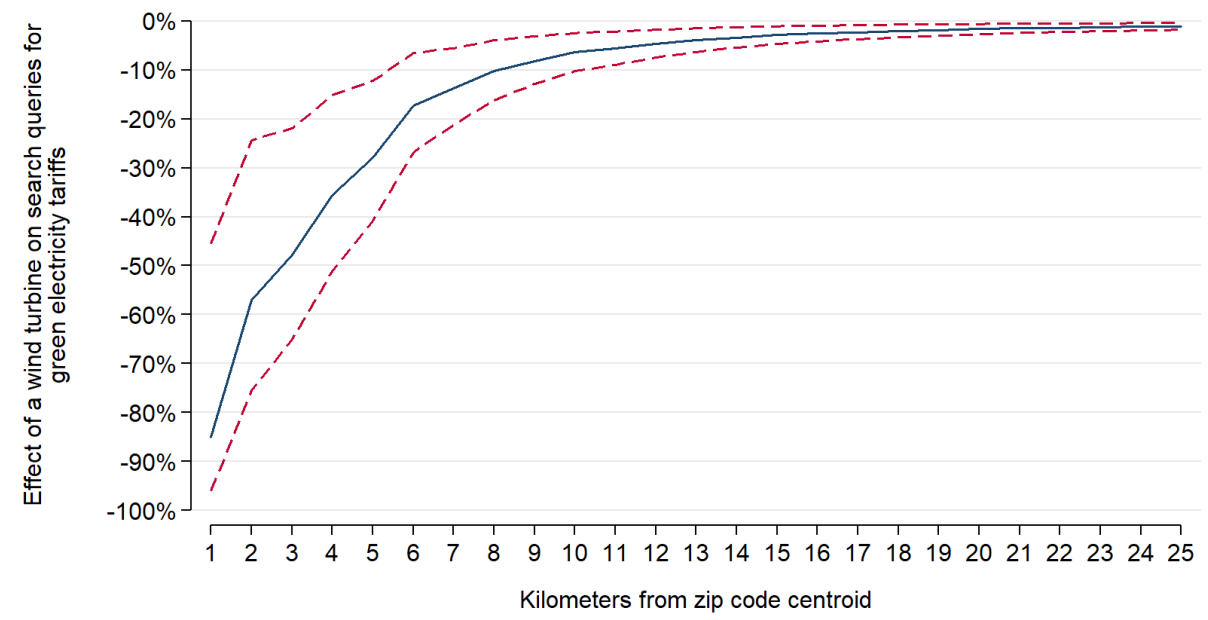

Notes: The figure plots the point estimates transformed into percentage effects $\left.\left(e^{\beta}-1\right) * 100\right)$ and the corresponding $90 \%$ confidence intervals of the effect of wind turbines on green electricity searches estimated in $1 \mathrm{~km}$ increments. 
We also examine treatment heterogeneity across different sub-populations. We do this by estimating our model on sub-samples split according to the median values of (i) the share of young households, (ii) income levels (average purchasing power per household), or (iii) urbanization. The results are shown as percentage effects in Figure 10 and reveal negative treatment effects for all groups, with those for wealthier and rural households being particularly large. Further, we also observe that the effect appears to be more pronounced among older people, conditional on the household searching online. The corresponding Table is shown in the Appendix (Table A5).

\section{Figure 10: Effect of Wind Turbines on Green Electricity Searches: Sample Split}
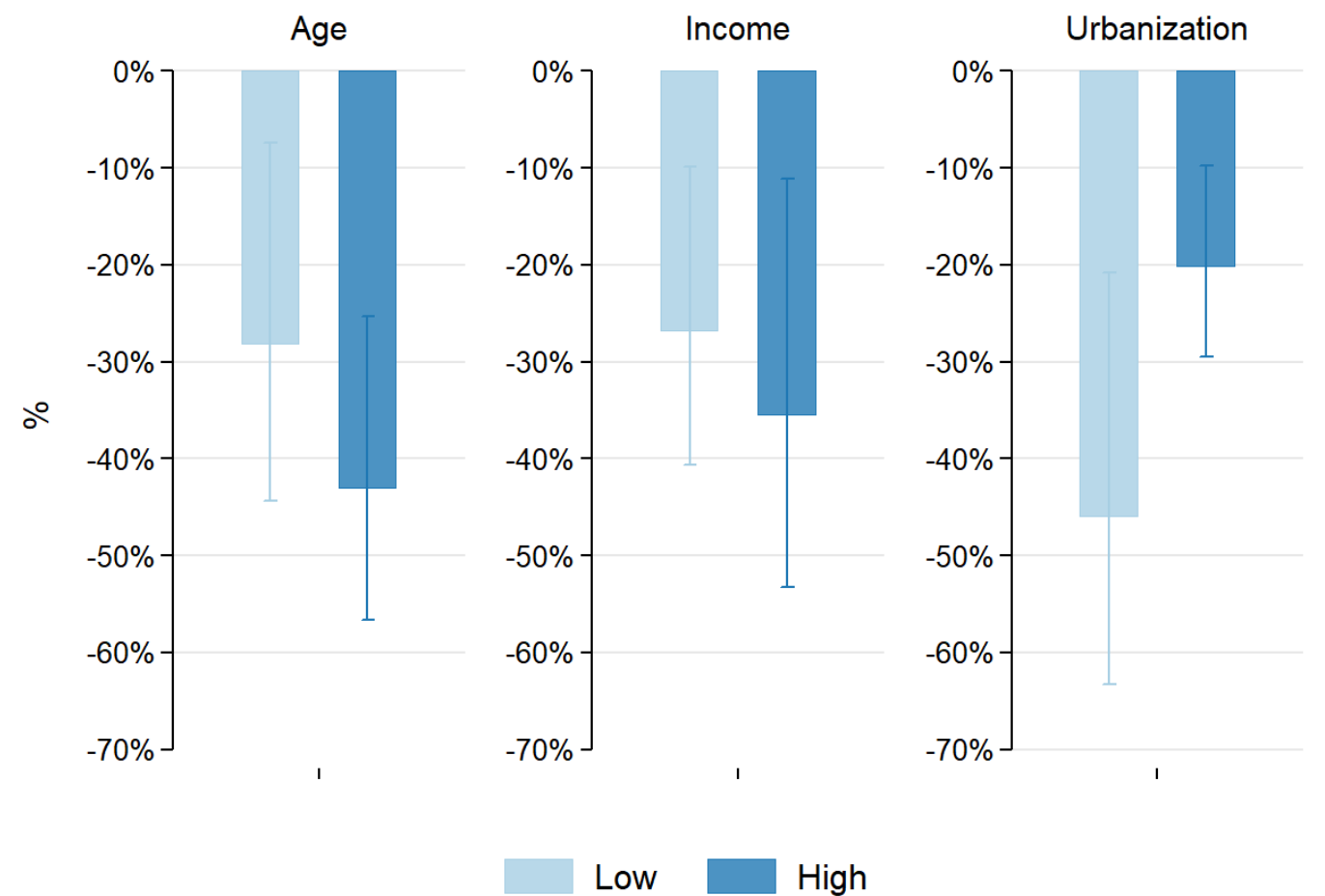

Notes: The figure plots the point estimates transformed into percentage effects $\left.\left(e^{\beta}-1\right) * 100\right)$ and the corresponding $90 \%$ confidence intervals of the effect of wind turbines on green electricity searches for different subpopulations.

Finally, in Appendix Table A6, we report estimation results when the explanatory variable is wind power capacity instead the number of turbines. The coefficient estimates imply that increasing installed capacity in a zip code by 1 MW decreases preferences for green tariffs by 20 percent. $^{30}$ Again, this coefficient rapidly declines

\footnotetext{
${ }^{30}$ The average net capacity of a WT is $1.4 \mathrm{MW}$ in our data.
} 
with distance from the center of the zip code. Hence, the qualitative findings are very similar, regardless of whether the number or the capacity of WTs is the regressor of interest.

\subsection{Wind Turbines and Votes for the Green Party}

We now turn to our alternative measure of citizens' support for renewable energy. The research design is the same as in our analysis of tariff searches for green electricity, but instead of looking at zip-code-level outcomes for the years from 2011 until 2014, we analyze municipal vote shares for the Green Party in two German federal elections held in 2009 and 2013. As above, the first-stage results lend support to the relevance of the instruments and the Durbin-Wu-Hausman test corroborates our conjecture that endogeneity is an issue and hence such instruments are needed for consistent estimation.

The results are reported in Table 6 and imply that an additional WT in a municipality reduces election outcomes for the Green Party by 17 percent. ${ }^{31}$ As is the case with search queries, the impact of WTs on votes for the Green Party rapidly diminishes with distance from a municipality's centroid. Results from Poisson Pseudo Maximum Likelihood (PPML) estimations with a control function for endogeneity are again similar to those from the linear IV regressions (cf. Appendix Table A11).

${ }^{31} e^{-0.184}-1$ 
Table 6: Effect of Wind Turbines on Green Party Voting Shares

\begin{tabular}{|c|c|c|c|c|c|c|c|}
\hline & \multicolumn{7}{|c|}{ Dependen variable is $\log$ (voting share) } \\
\hline & $(1)$ & $(2)$ & (3) & (4) & (5) & $(6)$ & $(7)$ \\
\hline No. WT within municipality & $\begin{array}{c}-0.184^{* * *} \\
(0.053)\end{array}$ & & & & & & \\
\hline No. WT within $1 \mathrm{~km}$ & & $\begin{array}{c}-0.239^{* * *} \\
(0.070)\end{array}$ & & & & & \\
\hline No. WT within $2 \mathrm{~km}$ & & & $\begin{array}{c}-0.127^{* * *} \\
(0.036)\end{array}$ & & & & \\
\hline No. WT within $3 \mathrm{~km}$ & & & & $\begin{array}{c}-0.069^{* * *} \\
(0.018)\end{array}$ & & & \\
\hline No. WT within $5 \mathrm{~km}$ & & & & & $\begin{array}{c}-0.024^{* * *} \\
(0.006)\end{array}$ & & \\
\hline No. WT within $10 \mathrm{~km}$ & & & & & & $\begin{array}{c}-0.007^{* * *} \\
(0.002)\end{array}$ & \\
\hline No. WT within $20 \mathrm{~km}$ & & & & & & & $\begin{array}{r}-0.002^{* * * *} \\
(0.001)\end{array}$ \\
\hline Population & $\begin{array}{l}-0.005 \\
(0.003)\end{array}$ & $\begin{array}{l}-0.002 \\
(0.002)\end{array}$ & $\begin{array}{l}-0.003 \\
(0.002)\end{array}$ & $\begin{array}{l}-0.003 \\
(0.002)\end{array}$ & $\begin{array}{c}-0.002 \\
(0.002)\end{array}$ & $\begin{array}{l}-0.002 \\
(0.002)\end{array}$ & $\begin{array}{l}-0.002 \\
(0.001)\end{array}$ \\
\hline Young $\mathrm{HH}$ & $\begin{array}{c}0.000 \\
(0.002)\end{array}$ & $\begin{array}{l}-0.000 \\
(0.002)\end{array}$ & $\begin{array}{l}-0.001 \\
(0.002)\end{array}$ & $\begin{array}{l}-0.000 \\
(0.002)\end{array}$ & $\begin{array}{l}-0.000 \\
(0.002)\end{array}$ & $\begin{array}{l}-0.000 \\
(0.002)\end{array}$ & $\begin{array}{l}-0.000 \\
(0.002)\end{array}$ \\
\hline Unemployment & $\begin{array}{c}-0.005^{* *} \\
(0.002)\end{array}$ & $\begin{array}{l}-0.002 \\
(0.002)\end{array}$ & $\begin{array}{l}-0.003 \\
(0.002)\end{array}$ & $\begin{array}{l}-0.003^{*} \\
(0.002)\end{array}$ & $\begin{array}{l}-0.003 \\
(0.002)\end{array}$ & $\begin{array}{c}-0.002 \\
(0.002)\end{array}$ & $\begin{array}{c}-0.002 \\
(0.002)\end{array}$ \\
\hline Year FE & Yes & Yes & Yes & Yes & Yes & Yes & Yes \\
\hline Municipality FE & Yes & Yes & Yes & Yes & Yes & Yes & Yes \\
\hline Durbin-Wu-Hausman test & 0.00 & 0.00 & 0.00 & 0.00 & 0.00 & 0.00 & 0.01 \\
\hline First stage F stat. & 42.61 & 31.77 & 51.74 & 73.77 & 129.25 & 273.24 & 482.53 \\
\hline Obs. & 20,158 & 20,158 & 20,158 & 20,158 & 20,158 & 20,158 & 20,158 \\
\hline
\end{tabular}

Notes: Standard errors clustered at the municipality level in parenthesis. Estimation by 2SLS. Construction of wind turbines is considered endogenous. Instruments based on expected revenues of a WT according to the reference yield model. The period under investigation covers the elections 2009 and 2013 . ${ }^{* * *} p<1 \%$, ${ }^{* *} p<5 \%,{ }^{*} p<10 \%$. 


\section{Figure 11: Effect of Wind Turbines on Voting Shares for the Green Party: Distance}

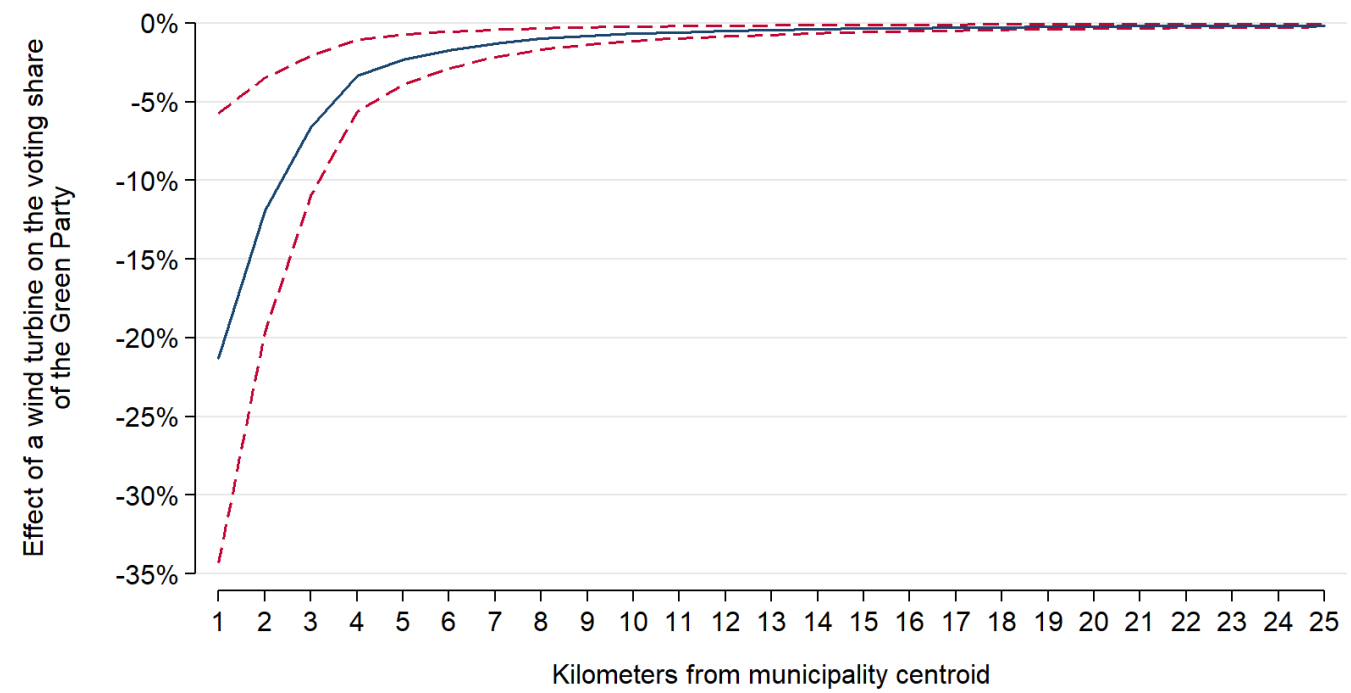

Notes: The figure plots the point estimates transformed into percentage effects $\left.\left(e^{\beta}-1\right) * 100\right)$ and the corresponding $90 \%$ confidence intervals of the effect of wind turbines on voting shares for the Green Party estimated in $1 \mathrm{~km}$ increments.

As before, we also analyze potentially heterogeneous effects of WT penetration across different subpopulations. The percentage effects are shown in Figure 12 and the corresponding tables can be found in Appendix Table A9. Again, the effect is greatest among older people, in less populated areas and those where unemployment is low. 


\section{Figure 12: Effect of Wind Turbines on Green Party Vote Shares: Sample Split}
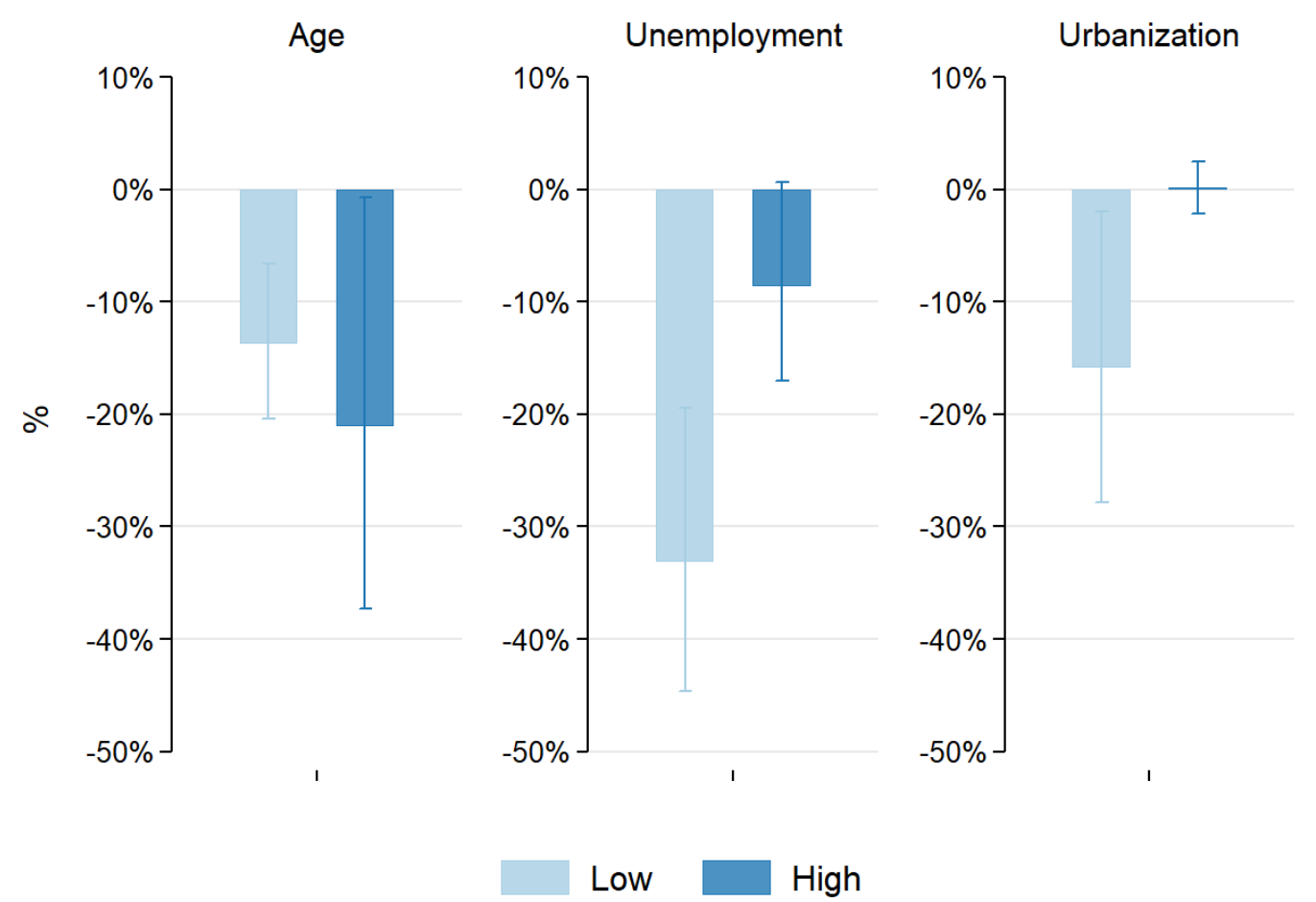

Notes: The figure plots the point estimates transformed into percentage effects $\left.\left(e^{\beta}-1\right) * 100\right)$ and the corresponding $90 \%$ confidence intervals of the effect of wind turbines on voting shares for the Green Party for different subpopulations.

\subsection{Extensions}

Effects of the first wind turbine. One may conjecture that the perception of an additional WT critically depends on whether or not the population is already exposed to them. In particular, a negative perception is likely higher when going from zero to $n$ WTs than when adding those $n$ WTs to an existing stock. Such cases are quite relevant in our data. 8,075 out of 10,003 municipalities had not a single WT installed by 2009, and 6,011 out of 8,039 zip codes had no wind turbine installed by 2011. By the end of the respective sample periods, 425 municipalities and 303 zip codes had seen the installation of the first WT on their territory. Do new wind turbines have a stronger effect on citizens' support in those areas than overall?

To investigate this, we re-estimate the specifications from Column (1) in Tables 4 and 6 after excluding all regions that already had at least one WT at the beginning of the observation period. The results, reported in Appendix Tables A7 and A12, show 
that the estimated effects are indeed substantially larger than in the full sample. Firsttime installation of a WT in a zip code reduces the share of green tariff queries by as much as 81 percent, suggesting that people in these areas then almost entirely dismiss renewable energy tariffs. ${ }^{32}$ Similarly, votes for the Green Party drop by 38 percent in municipalities that had no WTs in 2009 but at least one in 2013, as compared to municipalities that remained without any WT until at least 2013. ${ }^{33}$

It bears noting that the exclusion of locations that already had WTs in 2009 and 2011, respectively, substantially decreases variation in the data. This reduces the power of our instrument, as indicated by the rather low first-stage F-statistics of 13.28 and 7.82, respectively. According to the critical values of Stock and Yogo (9.08 and 6.46, respectively), the estimates of the voting share may suffer from a bias in the range of 10 percent to 20 percent. However, even in light of this consideration the effect of the first WTs remains substantially larger than in the full sample.

Other elections. So far we have focused on how WTs affect the local voting behavior at federal elections. This appears reasonable as the course of Germany's energy transition is basically set at the federal level. In principle, one could also think about having a deeper look at outcomes of local elections. However, this setting is often dominated by so-called "independent voters' associations" formed by citizens who pursue local objectives despite very heterogeneous ideological stances. Since the Green Party does not even run candidates for the municipal council in 66 percent of German municipalities, we refrain from analyzing local election outcomes. ${ }^{34}$

It is possible, however, to estimate the impact of WTs on the outcomes of elections to the European Parliament (EP). These elections are commonly perceived as secondorder elections and often misused as "second-order-national-contests" where voters express their dissatisfaction with a party's national politics (Hix and Marsh, 2007). The logic behind this is that long-term supporters of a political party are reluctant

${ }^{34} \mathrm{An}$ additional reason for not using local elections is that party positions at the municipality and state levels often deviate in non-negligible ways from the position at the federal level. Partly, such discrepancies can be seen as a reaction to fierce competition from independent voter associations.
} 
to express their disenchantment by voting for another party at a first-order (e.g., a federal) election, but are willing to cast a vote of dissatisfaction with their party in a second-order election. In line with this hypothesis we find somewhat larger effects when re-estimating the model on EP election data, as reported in Appendix Table A13. The coefficient estimates imply that an additional WT reduces the vote share of the Green Party by 22 percent (compared to 17 percent in the Bundestag elections). ${ }^{35}$

Placebo analysis. To assess the possibility that our results are driven by pure chance, we propose a placebo regression analysis. To this end, we randomly assign the observed combinations of wind turbine deployment and instrumental variables to another zip code or municipality, for all years. For instance, the WT data and the corresponding instrument in zip code $i$ in the years 2011 to 2014 are randomly assigned to zip code $j$ for the corresponding years. This procedure ensures relevance of the instruments for WT expansion to the same extent as in the original specification, yet there should no longer be a systematic relationship with green tariff searches or green vote shares, since the assignment of WTs to the dependent variable is now random. ${ }^{36}$

For each of the baseline specifications in Column (1) of Tables 4 and 6, we re-estimate the model on the modified data and store the coefficient estimate and $p$-value obtained for WT. We repeat this procedure 1,000 times and plot the distributions of placebo coefficients and $p$ values in Figures 13 (electricity tariff searches) and 14 (Green Party votes).

For both outcome variables, the results strongly suggest that the estimation results are not an artifact of random chance. The placebo regressions yield mean coefficient estimates of 0.00 and $p$-values of 0.5 , which is in stark contrast with the negative and highly significant treatment effects obtained above. In line with the random assignment of wind turbines to outcomes in the placebo treatment, the $p$-values exceed 0.1 level in 90 percent of cases, and the Durbin-Wu-Hausmann tests no longer reject exogeneity. The result that randomly assigning treatment across localities leads to rather precise

\footnotetext{
$35 e^{-0.243}-1$.

${ }^{36}$ We keep the socio-economic control variables in their original location. However, the results of the placebo tests do not change if they are randomized along with the WTs.
} 
Figure 13: Placebo Analysis of Green Electricity Searches: Distribution of Treatment Coefficients (a) and $p$-values (b)

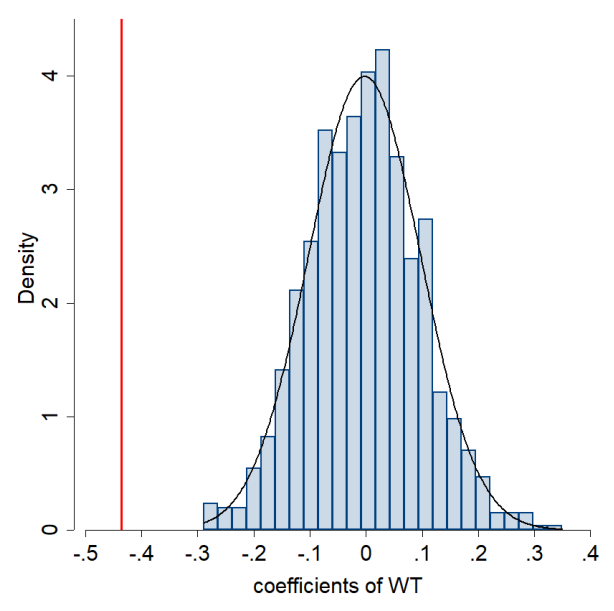

(a)

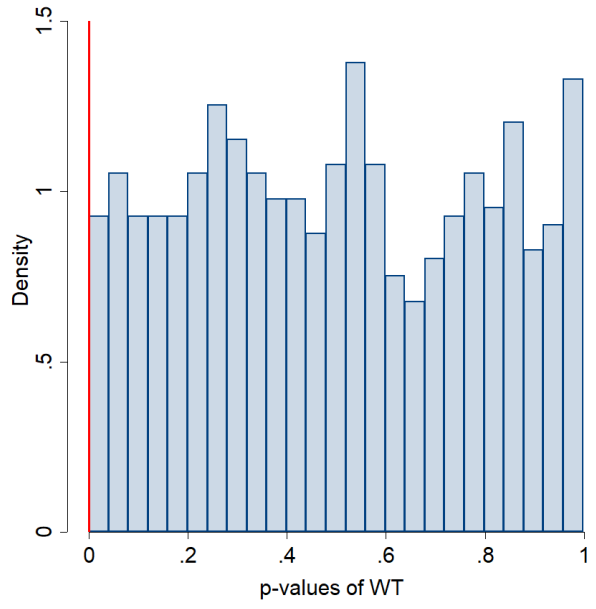

(b)

Notes: The red vertical lines indicate estimation results from Column (1) in Table 4, with a point estimate of $-0.44(p=0.00)$. The black line presents a normal distribution. Durbin-Wu-Hausman's $p=0.49$.

Figure 14: Placebo Analysis of Green Vote Shares: Distribution of Treatment Coefficients (a) and $p$-values (b)

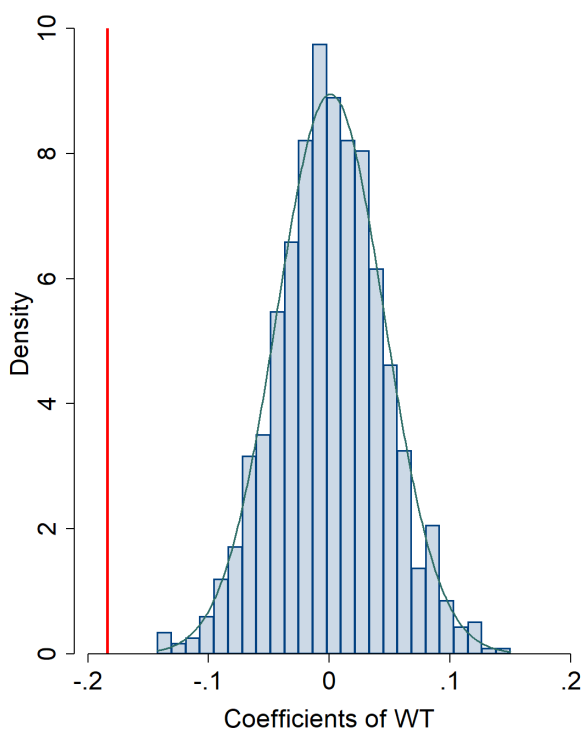

(a)

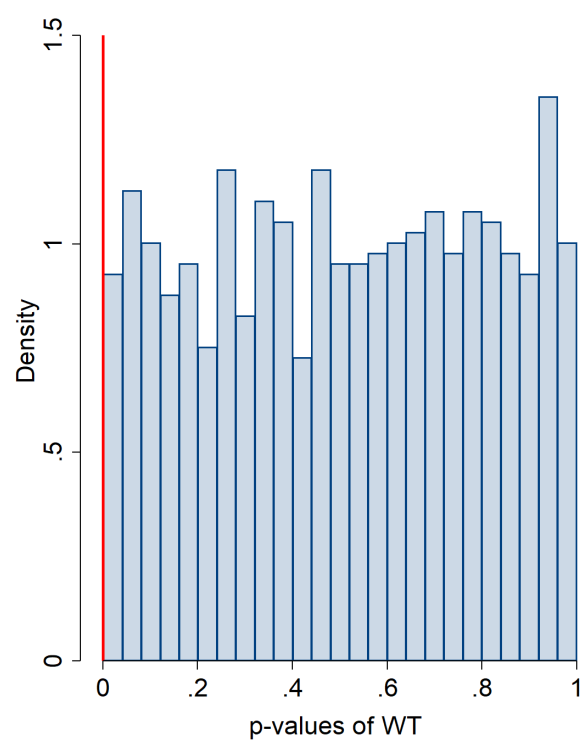

(b)

Notes: The red vertical lines indicate estimation results from Column (1) in Table 4, with a point estimate of $-0.18(p=0.00)$. The black line presents a normal distribution. Durbin-Wu-Hausman's $p=0.50$. 
zero estimates for both outcome variables and hence strengthens the confidence in our main findings.

\section{Financial Participation and Support for Renewables}

Our results have shown that proximity to wind turbines lowers revealed-preference measures of citizens' support for renewable energy. Hence, minimum requirements on distances for the construction of new wind turbines to residential areas, which have been introduced in German federal and state laws, could be effective at securing support for a continued wind power expansion. However, minimum distance requirements are controversial because they can dramatically limit the remaining set of suitable construction sites, thereby putting in jeopardy the successful transformation of the energy system. This is why there is great interest in alternative policy instruments that avoid such trade-offs. In the public debate, particular attention has been given to financial participation as a possible cure for NIMBYism. The idea behind this is to compensate affected residents for the local externalities of renewable electricity generation. In this section, we explore whether our data and setting lend empirical support to the effectiveness of such an idea.

Transferring revenues from wind power plants to affected communities would be a direct form of financial participation and could be implemented within existing schemes of local taxation in Germany. For example, profits of wind power plants are subject to commercial taxes levied by municipal governments. However, if the company operating the WT is not headquartered in the same municipality as the WT, the tax base is divided between municipalities. Until 2009 this division was based on the company's labor cost share in each municipality. Given that WTs - once operational - only incur minimal labour costs, municipalities with WTs did not gain much tax revenue in this setting. This changed in 2009 when new rules were introduced that allocate 70 percent of commercial tax revenues from WTs based on the book value of tangible fixed assets, and only 30 percent according to labor cost shares. 
The reform was intended to increase commercial tax revenues of municipalities that host wind turbines. We test whether this goal was achieved by regressing the commercial tax base on wind turbines in our panel of German municipalities from 2009 until 2015. ${ }^{37}$ Since new WTs begin to contribute to commercial taxes only in the year after they have been installed, we lag WT by one year. We estimate this relationship in first differences and instrument for WT deployment as in our main specification. ${ }^{38}$ The estimation results, reported in Appendix Table A14, imply that the installation of an additional WT increases the commercial tax base by about 11 to 15 percent in profits in the subsequent year. At the median, this is equivalent to an increase in the annual tax base by around 10 to 13 thousand Euros in the following year for one additional wind turbine. The estimates are statistically significant at the $90 \%$ level or better and control for unobserved heterogeneity across municipalities and aggregate shocks at the annual level.

If German municipalities have indeed financially benefited from wind power expansion, as this finding suggests, we can exploit the variation in financial benefits across municipalities to learn about the effect of financial participation on local support for renewables. To measure financial participation, we exploit variation in the municipalities' commercial tax revenues from the tax change in 2009. Under the new regime, regions with wind turbines experienced an increase in their commercial tax revenues (holding all other factors constant), if they were not hosting the headquarters of the wind turbine operator. Thus, the tax change induces variation in local commercial tax revenues from wind turbines without being confounded with changes in the number of wind turbines installed. Since we do not observe the location of headquarters, we cannot directly assess which region benefited. We therefore estimate potential gains from this tax change by regressing the change in commercial tax revenues from 2008

\footnotetext{
${ }^{37}$ We use the tax base instead of tax revenues since the tax base accounts for differential commercial tax rates set by the municipalities. Local governments may change these tax rates in response to wind power expansion as shown by Langenmayr and Simmler (2017).

${ }^{38} \mathrm{We}$ instrument lagged wind turbine expansion with lagged expected revenues, lagged ineligibility times wind potential and lagged ineligibility.
} 
Table 7: Effect of Wind Turbines on Citizen's Support and the role of local commercial tax revenues

\begin{tabular}{lcc}
\hline & $\begin{array}{c}\log \text { (first query) } \\
(1)\end{array}$ & $\begin{array}{c}\log \text { (voting share) } \\
(2)\end{array}$ \\
\hline No. WTs & $-0.532^{* * *}$ & $-0.163^{* * *}$ \\
& $(0.132)$ & $(0.052)$ \\
No. WTs x Tax benefit & $0.348^{* *}$ & $0.064^{* *}$ \\
& $(0.138)$ & $(0.027)$ \\
Population & $0.047^{* *}$ & -0.005 \\
& $(0.020)$ & $(0.003)$ \\
Young HH & -0.014 & 0.000 \\
& $(0.010)$ & $(0.001)$ \\
Purchasing power & 0.012 & \\
& $(0.008)$ & $-0.005^{*}$ \\
Unemployment & & $(0.003)$ \\
& & 0.01 \\
\hline Durbin-Wu-Hausman test & 0.00 & 19.59 \\
First stage F stat. & 36.10 & 19,972 \\
Obs. & 31,297 & \\
\hline
\end{tabular}

Notes: All estimations are done in first differences and include year fixed effects. Standard errors clustered at the municipality and zip code level in parenthesis, respectively. Estimation by 2SLS. The local adoption rate of wind power is considered endogenous. Instruments based on expected revenues of a WT according to the reference yield model. The estimation period refers to 2011 to 2014 for renewable queries and 2009 and 2013 for Green voting shares, respectively. ${ }^{* * *} p<1 \%,{ }^{* *} p<5 \%,{ }^{*} p<10 \%$. 
to 2009 on lagged WT and the socioeconomic controls from the main specifications. ${ }^{39}$ Controlling for installed wind turbines, regions with positive residuals in 2009 likely benefited from the new tax regime. We define an indicator variable for beneficiaries of the policy change which is one for regions with positive residuals and at least one wind turbine installed. We estimate eq. (1) augmented by the interaction of the number of wind turbines with this indicator variable.

The results are reported in Table 7. The point estimates on WT in the baseline group, i.e. for regions that did not benefit from the tax change for wind turbines, resemble those of our main results and are statistically significant at conventional levels. ${ }^{40}$ The coefficient estimates on the interaction of interest is positive and statistically significant, suggesting that the negative effect from wind turbines on both support measures is alleviated for those regions that benefited from the tax change on wind power profits.

Overall, these results provide suggestive evidence to support the notion that a higher local participation in wind power profits mitigates the negative impact of nearby installation of wind turbine on citizen's support for renewable energy.

\section{Conclusion}

Model scenarios unequivocally show that mitigating global climate change requires a dramatic expansion of renewable energy in the years and decades to come. In liberal societies, the success of such a strategy crucially depends on public acceptance and citizen's support for renewable energy. While opinion polls consistently find broad support for renewable energy among citizens, concrete projects are often met by fierce local opposition. The NIMBY phenomenon is particularly wide-spread in the context of wind power plants and poses a serious obstacle for a successful energy transition.

In this paper, we estimate the impact of increasing wind power exposure on citizen's support for renewable energy using Germany as a case study. We apply two measures

\footnotetext{
${ }^{39}$ For the analyses of search requests on the zip code level, we use the commercial tax base of the municipality that is associated with the respective zip code whenever this is possible. Otherwise we need to exclude these observations from the analyses.

${ }^{40}$ For renewable tariff queries, the point estimate is a bit larger than in the baseline specification, while the one for votes is in a similar range.
} 
for citizen's support: local preferences for renewable energy electricity tariffs and election outcomes for the Green Party. Using the first measure, we find that search queries for renewable energy tariffs made on price comparison websites drop by around 35 percent when a wind turbine is installed in the zip code. Similarly, we find that votes for the Green Party in German federal elections decrease by about 17 percent with each new wind turbine in a municipality. These findings indicate that even strong and active proponents of renewable energy, i.e. consumers who actively search for green electricity and voters of the Green Party, significantly reduce their support when exposed to nearby wind turbines.

From a policy point-of-view, our results emphasize the urgency of bringing society on board with continued renewable energy expansion in order to achieve climate targets. Our analysis contributes evidence pertaining to two possible solutions. The first one is to enforce minimum distances between wind parks and populated areas. Our results support the view that minimum distance requirements are effective at mitigating negative effects on citizen's support. Minimum-distance policies are controversial, however, because they drastically limit the available space for building new wind turbines onshore. An alternative solution is to provide financial compensation to residents living close to wind turbines. We have focused on a mechanism by which revenues from local wind power projects are redistributed among residents via existing schemes of commercial taxation. According to our analysis, wind energy expansion has significantly increased tax revenues from such schemes, and this has been associated with smaller negative effects of wind turbines on citizen's support. Our policy recommendation is thus to enhance financial participation in the economic benefits from wind projects as the principal means of consolidating support for renewable energy among local residents.

\section{References}

Aitken, M. (2010). Why we still don't understand the social aspects of wind power: A critique of key assumptions within the literature. Energy Policy, 38(4):1834-1841. 
Behnisch, M., Schorcht, M., Kriewald, S., and Rybski, D. (2019). Settlement percolation: A study of building connectivity and poles of inaccessibility. Landscape and Urban Planning, 191:103631.

BMWi (2020). Time Series for the Development of Renewable Energy Sources in Germany. German Federal Ministry for Economic Affairs and Energy (BMWi).

BMWi (2021). Gesamtausgabe der Energiedaten. German Federal Ministry for Economic Affairs and Energy (BMWi).

Böttcher, J. (2010). Finanzierung von Erneuerbare-Energien-Vorhaben. Walter de Gruyter.

Bündnis 90/Die Grünen (2009). Bundestagswahlprogramm.

Bündnis 90/Die Grünen (2013). Bundestagswahlprogramm.

China Energy Portal (2021). Tracking China's transition to sustainable energy. https: //chinaenergyportal .org/en/2020-electricity-other-energy-statisticspreliminary/. Accessed 5th May, 2021.

Comin, D. and Rode, J. (2015). From green users to green voters. NBER Working Paper No. 19219.

Crain, W. M. (1977). On the structure and stability of political markets. Journal of Political Economy, 85(4):829-842.

Dastrup, S. R., Zivin, J. G., Costa, D. L., and Kahn, M. E. (2012). Understanding the Solar Home price premium: Electricity generation and "Green" social status". European Economic Review, 56(5):961 - 973.

Davis, L. W. (2011). The effect of power plants on local housing values and rents. The Review of Economics and Statistics, 93(4):1391-1402.

EEG (2004). Konsolidierte Begründung zu dem Gesetz für den Vorrang Erneuerbarer Energien 2004. https://www . erneuerbare-energien.de/EE/Redaktion/DE/Gese tze-Verordnungen/eeg_begruendung_2004.pdf. Accessed 23th August, 2021.

EEG (2009). Konsolidierte Begründung zu dem Gesetz für den Vorrang Erneuerbarer Energien 2009. https://www . clearingstelle-eeg-kwkg.de/sites/default/fil es/A10-EEG_2009_konsolidierte_Begr_0.pdf. Accessed 23th August, 2021.

European Commission (2018). A Clean Planet for all - A European long-term strategic vision for a prosperous, modern, competitive and climate neutral economy, INDEPTH ANALYSIS IN SUPPORT OF THE COMMISSION COMMUNICATION.

German Transmission System Operators (2019). Remuneration and apportionment categories. https://wWw . netztransparenz . de/EEG/Verguetungs-und-Umlagekat egorien. Accessed 23th August, 2019.

Gibbons, S. (2015). Gone with the wind: Valuing the visual impacts of wind turbines through house prices. Journal of Environmental Economics and Management, 72:177 196. 
Haan, P. and Simmler, M. (2018). Wind electricity subsidies - a windfall for landowners? evidence from a feed-in tariff in germany. Journal of Public Economics, 159:16-32.

Hausman, J. (2012). Contingent valuation: From dubious to hopeless. Journal of Economic Perspectives, 26(4):43-56.

Heintzelman, M. D. and Tuttle, C. M. (2012). Values in the wind: A hedonic analysis of wind power facilities. Land Economics, 88(3):571-588.

Hitaj, C. and Löschel, A. (2019). The impact of a feed-in tariff on wind power development in Germany. Resource and Energy Economics, 57:18-35.

Hix, S. and Marsh, M. (2007). Punishment or protest? understanding european parliament elections. The Journal of Politics, 69(2):495-510.

IPCC (2018). Global warming of $1.5^{\circ} \mathrm{c}$. Intergovernmental Panel on Climate Change (IPCC), Special Report.

Jacobsen, G. D., Kotchen, M. J., and Vandenbergh, M. P. (2012). The behavioral response to voluntary provision of an environmental public good: Evidence from residential electricity demand. European Economic Review, 56(5):946 - 960.

Jarvis, S. (2021). The economic costs of nimbyism. Mimeograph. University of Mannheim.

Jensen, C. U., Panduro, T. E., and Lundhede, T. H. (2014). The vindication of don quixote the impact of noise and visual pollution from wind turbines. Land Economics, 90(4):668-682.

Kling, C. L., Phaneuf, D. J., and Zhao, J. (2012). From exxon to bp: Has some number become better than no number? Journal of Economic Perspectives, 26(4):3-26.

Kotchen, M. J. and Moore, M. R. (2007a). Conservation: From voluntary restraint to a voluntary price premium. Environmental and Resource Economics, 40(2):195-215.

Kotchen, M. J. and Moore, M. R. (2007b). Private provision of environmental public goods: Household participation in green-electricity programs. Journal of Environmental Economics and Management, 53(1):1 - 16.

Krekel, C. and Zerrahn, A. (2017). Does the presence of wind turbines have negative externalities for people in their surroundings? Evidence from well-being data. Journal of Environmental Economics and Management, 82:221 - 238.

Langenmayr, D. and Simmler, M. (2017). Why the current tax rate tells you little: Competing for mobile and immobile firms. CESifo Working Paper No. 6827.

Ma, C., Rogers, A. A., Kragt, M. E., Zhang, F., Polyakov, M., Gibson, F., Chalak, M., Pandit, R., and Tapsuwan, S. (2015). Consumers' willingness to pay for renewable energy: A meta-regression analysis. Resource and Energy Economics, 42:93 - 109.

Mattmann, M., Logar, I., and Brouwer, R. (2016a). Hydropower externalities: A metaanalysis. Energy Economics, 57:66 - 77. 
Mattmann, M., Logar, I., and Brouwer, R. (2016b). Wind power externalities: A metaanalysis. Ecological Economics, 127:23 - 36.

Menges, R., Schröder, C., and Traub, S. (2005). Altruism, warm glow and the willingness-to-donate for green electricity: An artefactual field experiment. Environmental and Resource Economics, 31(4):431-458.

Roback, J. (1982). Wages, rents, and the quality of life. Journal of Political Economy, 90(6):1257-1278.

Rode, J. (2014). Not in My Backyard! Local Resistance to the Adoption of Renewables. mimeo.

Rosen, S. (1974). Hedonic prices and implicit markets: Product differentiation in pure competition. Journal of Political Economy, 82(1):34-55.

Stokes, L. C. (2016). Electoral backlash against climate policy: A natural experiment on retrospective voting and local resistance to public policy. American Journal of Political Science, 60(4):958-974.

Sunak, Y. and Madlener, R. (2016). The impact of wind farm visibility on property values: A spatial difference-in-differences analysis. Energy Economics, 55:79 - 91.

Sundt, S. and Rehdanz, K. (2015). Consumers' willingness to pay for green electricity: A meta-analysis of the literature. Energy Economics, 51:1 - 8.

U.S. Energy Information Administration (2021). Wind explained Electricity generation from wind. https://www.eia.gov/energyexplained/wind/electricity-gener ation-from-wind.php. Accessed 5th May, 2021.

van der Horst, D. (2007). NIMBY or not? Exploring the relevance of location and the politics of voiced opinions in renewable energy siting controversies. Energy Policy, 35(5):2705 - 2714.

von Möllendorff, C. and Welsch, H. (2017). Measuring renewable energy externalities: Evidence from subjective well-being data. Land Economics, 93(1):109-126. 


\section{A Appendix}

\section{A.1 Additional tables}

Table A1: First-stage regression for the green tariff query analysis

(1)

\begin{tabular}{lc} 
& $(1)$ \\
& No. WT within zip code \\
\hline Expected revenue of a WT & $0.660^{* * *}$ \\
& $(0.130)$ \\
Ineligible & $0.704^{* * *}$ \\
& $(0.061)$ \\
Ineligible $\times$ Wind potential & 0.014 \\
& $(0.052)$ \\
Population & $-0.046^{*}$ \\
& $(0.024)$ \\
Young HH & -0.006 \\
& $(0.005)$ \\
Purchasing power & $-0.007^{*}$ \\
& $(0.004)$ \\
\hline Year FE & Yes \\
Zip code FE & Yes \\
Obs. & 32,252 \\
\hline
\end{tabular}

Notes: Standard errors clustered at the zip code level in parenthesis. ${ }^{* * *} p<1 \%,{ }^{* *} p<5 \%,{ }^{*} p<10 \%$.

Table A2: Effect of the number of WTs on search queries for green tariffs - OLS estimates

\begin{tabular}{lc}
\hline & $(1)$ \\
& $\log ($ first query $)$ \\
\hline No. WT within zip code & $-0.027^{* * *}$ \\
& $(0.009)$ \\
Population & $0.066^{* * *}$ \\
& $(0.018)$ \\
Young HH & -0.009 \\
& $(0.009)$ \\
Purchasing power & $0.015^{* *}$ \\
& $(0.007)$ \\
\hline Year FE & Yes \\
Zip code FE & Yes \\
Obs. & 32,252 \\
\hline Notes: Standard errors clustered at the zip \\
codelevel in parenthesis. ${ }^{* * *} p<1 \%,{ }^{* *} p<5 \%$, \\
${ }^{*} p<10 \%$.
\end{tabular}


Table A3: Effect of the number of WTs on search queries for green tariffs controlling for land prices and network charges

\begin{tabular}{lc}
\hline & $(1)$ \\
& $\log ($ first query) \\
\hline No. WT within zip code & $-0.422^{* * *}$ \\
& $(0.117)$ \\
Population & $0.038^{*}$ \\
& $(0.023)$ \\
Young HH & $-0.021^{* *}$ \\
& $(0.010)$ \\
Purchasing power & 0.012 \\
& $(0.008)$ \\
Land prices & -0.098 \\
& $(0.146)$ \\
Grid charges per-unit component & 0.041 \\
& $(0.025)$ \\
Grid charges fix component & -0.003 \\
& $(0.002)$ \\
\hline Year FE & Yes \\
Zip code FE & Yes \\
Durbin-Wu-Hausman test & 0.00 \\
First stage F stat. & 56.89 \\
Obs. & 27,870 \\
\hline
\end{tabular}

Notes: Standard errors clustered at the zip code level in parenthesis. Estimation by 2SLS. The local adoption rate of wind power is considered endogenous. Instruments based on expected revenues of a WT according to the reference yield model. ${ }^{* * *} p<1 \%,{ }^{* *} p<5 \%$, ${ }^{*} p<10 \%$. 
Table A4: Effect of the number of WTs on search queries for green tariffs - PPML estimation with control function

\begin{tabular}{lc}
\hline & $(1)$ \\
& first query \\
\hline No. WT within zip code & $-0.351^{* * *}$ \\
& $(0.094)$ \\
Population & $0.125^{* * *}$ \\
& $(0.026)$ \\
Young HH & -0.011 \\
& $(0.009)$ \\
Purchasing power & -0.001 \\
& $(0.008)$ \\
Control function & $0.339^{* * *}$ \\
& $(0.095)$ \\
\hline Year FE & Yes \\
Zip code FE & Yes \\
Obs. & 31,881 \\
\hline
\end{tabular}

Notes: Standard errors clustered at the zip code level in parenthesis. The local adoption rate of wind power is considered endogenous. Estimation by PPML with control function inclusion for endogeneity. . ${ }^{* * *} p<1 \%,{ }^{* *} p<5 \%,{ }^{*} p<10 \%$.

Table A5: Effect of Wind Turbines on Green Electricity Searches: Sample Split

\begin{tabular}{|c|c|c|c|c|c|c|}
\hline & \multicolumn{2}{|c|}{ Age } & \multicolumn{2}{|c|}{ Income } & \multicolumn{2}{|c|}{ Urbanization } \\
\hline & $\begin{array}{l}\text { young } \\
(1)\end{array}$ & $\begin{array}{l}\text { old } \\
\text { (2) }\end{array}$ & $\begin{array}{l}\text { low } \\
(3)\end{array}$ & $\begin{array}{l}\text { high } \\
(4)\end{array}$ & $\begin{array}{l}\text { rural } \\
(5)\end{array}$ & $\begin{array}{c}\text { urban } \\
\text { (6) }\end{array}$ \\
\hline \multirow[t]{2}{*}{ No. WT within zip code } & $-0.331^{* *}$ & $-0.564^{* * *}$ & $-0.313^{* *}$ & $-0.439^{* *}$ & $-0.617^{* * *}$ & $-0.226^{* * *}$ \\
\hline & $(0.155)$ & $(0.165)$ & $(0.127)$ & $(0.196)$ & $(0.234)$ & $(0.075)$ \\
\hline \multirow[t]{2}{*}{ Population } & $0.056^{* * *}$ & 0.006 & $0.064^{* * *}$ & $-0.084^{* *}$ & $0.135^{* *}$ & $0.079^{* * *}$ \\
\hline & $(0.021)$ & $(0.050)$ & $(0.023)$ & $(0.036)$ & $(0.063)$ & $(0.019)$ \\
\hline \multirow[t]{2}{*}{ Young $\mathrm{HH}$} & 0.007 & $-0.033^{*}$ & 0.007 & -0.019 & $-0.032^{* *}$ & 0.006 \\
\hline & $(0.011)$ & $(0.018)$ & $(0.013)$ & $(0.015)$ & $(0.016)$ & $(0.009)$ \\
\hline \multirow[t]{2}{*}{ Purchasing power } & 0.013 & 0.011 & 0.012 & 0.010 & 0.007 & $0.026^{* * *}$ \\
\hline & $(0.010)$ & $(0.011)$ & $(0.011)$ & $(0.010)$ & $(0.011)$ & $(0.007)$ \\
\hline Year FE & Yes & Yes & Yes & Yes & Yes & Yes \\
\hline Zip code FE & Yes & Yes & Yes & Yes & Yes & Yes \\
\hline Durbin-Wu-Hausman test & 0 & 0 & 0 & 0 & 0 & 0 \\
\hline First stage F stat. & 31.12 & 40.09 & 40.41 & 28.11 & 29.56 & 45.97 \\
\hline Mean of first query & 3.91 & 3.39 & 3.58 & 3.73 & 3.04 & 4.26 \\
\hline Obs. & 16,127 & 16,125 & 16,128 & 16,124 & 16,128 & 16,124 \\
\hline
\end{tabular}

Notes: The dependent variable is $\log$ (first query). Standard errors clustered at the zip code level in parenthesis. Estimation by 2SLS. The local adoption rate of wind power is considered endogenous. Instruments based on expected revenues of a WT according to the reference yield mode. The period under investigation covers the years 2011 to 2014 . $^{* * *} p<1 \%$, ${ }^{* *} p<5 \%,{ }^{*} p<10 \%$. 
Table A6: Effect of the installed capacity of WTs on search queries for green tariffs

\begin{tabular}{lc}
\hline & $(1)$ \\
& $\log$ (first query) \\
\hline Cap. WT within zip code & $-0.179^{* * *}$ \\
& $(0.046)$ \\
Population & $0.040^{*}$ \\
& $(0.021)$ \\
Young HH & -0.012 \\
& $(0.010)$ \\
Purchasing power & 0.011 \\
& $(0.007)$ \\
\hline Year FE & Yes \\
Zip code FE & Yes \\
Durbin-Wu-Hausman test & 0.00 \\
First stage F stat. & 65.15 \\
Obs. & 32,252 \\
\hline
\end{tabular}

Notes: Standard errors clustered at the zip code level in parenthesis. Estimation by 2SLS. The local adoption rate of wind power is considered endogenous. Instruments based on expected revenues of a WT according to the reference yield model. ${ }^{* * *} p<1 \%,{ }^{* *} p<5 \%,{ }^{*} p<10 \%$.

Table A7: Effect of the first WTs on search queries for green tariffs - estimations on a sample excluding areas that already had WTs at the beginning of the observation period

\begin{tabular}{lc}
\hline & $(1)$ \\
& $\log$ (first query) \\
\hline No. WT within zip code & $-1.708^{* * *}$ \\
& $(0.586)$ \\
Population & 0.012 \\
& $(0.040)$ \\
Young HH & -0.010 \\
& $(0.013)$ \\
Purchasing power & 0.003 \\
& $(0.011)$ \\
\hline Year FE & Yes \\
Zip code FE & Yes \\
Durbin-Wu-Hausman test & 0.00 \\
First stage F stat. & 13.28 \\
Obs. & 24,195 \\
\hline
\end{tabular}

Notes: Standard errors clustered at the zip code level in parenthesis. Estimation by 2SLS. The local adoption rate of wind power is considered endogenous. Instruments based on expected revenues of a WT according to the reference yield model. ${ }^{* * *} p<1 \%,{ }^{* *} p<5 \%,{ }^{*} p<10 \%$. 
Table A8: Effect of the number of WTs on election outcomes for the Green Party OLS estimations

\begin{tabular}{lc}
\hline & $(1)$ \\
& $\log ($ voting share $)$ \\
\hline No. WT within municipality & 0.004 \\
& $(0.003)$ \\
Population & -0.002 \\
& $(0.002)$ \\
Young HH & 0.000 \\
& $(0.002)$ \\
Unemployment & -0.002 \\
& $(0.002)$ \\
\hline Year FE & Yes \\
Municipality FE & Yes \\
Obs. & 20,158 \\
\hline
\end{tabular}

Notes: Standard errors clustered at the municipality level in parenthesis. ${ }^{* * *} p<1 \%,{ }^{* *} p<5 \%,{ }^{*} p<10 \%$.

Table A9: Effect of Wind Turbines on Green Party Vote Shares: Sample Split

\begin{tabular}{|c|c|c|c|c|c|c|}
\hline & \multicolumn{2}{|c|}{ Age } & \multicolumn{2}{|c|}{ Unemployment } & \multicolumn{2}{|c|}{ Urbanization } \\
\hline & $\begin{array}{c}\text { young } \\
(1)\end{array}$ & $\begin{array}{l}\text { old } \\
(2)\end{array}$ & $\begin{array}{l}\text { high } \\
\text { (3) }\end{array}$ & $\begin{array}{l}\text { low } \\
(4)\end{array}$ & $\begin{array}{l}\text { rural } \\
(5)\end{array}$ & $\begin{array}{c}\text { urban } \\
\text { (6) }\end{array}$ \\
\hline \multirow[t]{2}{*}{ No. WT within municipality } & $-0.148^{* * *}$ & $-0.237^{*}$ & -0.090 & $-0.403^{* * *}$ & $-0.173^{*}$ & 0.001 \\
\hline & $(0.049)$ & $(0.140)$ & $(0.059)$ & $(0.114)$ & $(0.093)$ & $(0.014)$ \\
\hline \multirow[t]{2}{*}{ Population } & -0.002 & $-0.034^{* *}$ & -0.003 & $-0.110^{* * *}$ & -0.227 & -0.001 \\
\hline & $(0.002)$ & $(0.015)$ & $(0.002)$ & $(0.038)$ & $(0.152)$ & $(0.001)$ \\
\hline \multirow[t]{2}{*}{ Young $\mathrm{HH}$} & -0.001 & 0.003 & 0.001 & -0.001 & -0.000 & $0.001^{* *}$ \\
\hline & $(0.002)$ & $(0.003)$ & $(0.002)$ & $(0.002)$ & $(0.002)$ & $(0.001)$ \\
\hline \multirow[t]{2}{*}{ Unemployment } & -0.004 & $-0.006^{*}$ & -0.002 & -0.009 & -0.004 & 0.001 \\
\hline & $(0.006)$ & $(0.004)$ & $(0.002)$ & $(0.009)$ & $(0.003)$ & $(0.001)$ \\
\hline Year FE & Yes & Yes & Yes & Yes & Yes & Yes \\
\hline Zip code FE & Yes & Yes & Yes & Yes & Yes & Yes \\
\hline Durbin-Wu-Hausman test & 0.01 & 0.09 & 0.10 & 0.01 & 0.05 & 0.57 \\
\hline First stage F stat. & 42.53 & 5.39 & 10.38 & 23.89 & 11.21 & 38.17 \\
\hline Mean of voting share & 8.18 & 6.52 & 6.41 & 8.27 & 6.87 & 7.86 \\
\hline Obs. & 10,738 & 9,420 & 9,266 & 10,892 & 9,420 & 10,738 \\
\hline
\end{tabular}

Notes: The dependent variable is $\log$ (voting share). Standard errors clustered at the municipality level in parenthesis. Estimation by 2SLS. The local adoption rate of wind power is considered endogenous. Instruments based on expected revenues of a WT according to the reference yield model. The period under investigation covers the elections 2009 to 2013. ${ }^{* * *} p<1 \%$, ${ }^{* *} p<5 \%$, ${ }^{*} p<10 \%$. 
Table A10: Effect of the installed capacity of WTs on election outcomes for the Green Party

\begin{tabular}{lc}
\hline & $(1)$ \\
& $\log ($ voting share) \\
\hline No. WT within municipality & \\
& \\
Cap. WT within municipality & $-0.088^{* * *}$ \\
& $(0.026)$ \\
Population & $-0.006^{*}$ \\
& $(0.004)$ \\
Young HH & 0.000 \\
& $(0.002)$ \\
Unemployment & $-0.005^{* *}$ \\
& $(0.002)$ \\
\hline Year FE & Yes \\
Municipality FE & Yes \\
Durbin-Wu-Hausman test & 0.00 \\
First stage F stat. & 42.86 \\
Obs. & 20,158 \\
\hline
\end{tabular}

Notes: Standard errors clustered at the municipality level in parenthesis. Estimation by 2SLS. The local adoption rate of wind power is considered endogenous. Instruments based on expected revenues of a WT according to the reference yield model. ${ }^{* * *} p<1 \%,{ }^{* *} p<5 \%,{ }^{*} p<10 \%$.

Table A11: Effect of the number of WTs on election outcomes for the Green Party PPML estimation with control function

(1)

\begin{tabular}{lc} 
& green votes \\
\hline No. WT within municipality & $-0.132^{* * *}$ \\
& $(0.029)$ \\
Population & $-0.002^{* * *}$ \\
& $(0.001)$ \\
Young HH & 0.000 \\
& $(0.001)$ \\
Unemployment & $-0.002^{* *}$ \\
& $(0.001)$ \\
Control function & $0.135^{* * *}$ \\
& $(0.029)$ \\
\hline Year FE & Yes \\
Municipality FE & Yes \\
Obs. & 20,152 \\
\hline
\end{tabular}

Notes: Standard errors clustered at the municipality level in parenthesis. The local adoption rate of wind power is considered endogenous. Estimation by PPML with control function inclusion for endogeneity. ${ }^{* * *} p<1 \%,{ }^{* *} p<5 \%$, ${ }^{*} p<10 \%$. 
Table A12: Effect of the first WTs on election outcomes for the Green Party estimations on a sample excluding areas that already had WTs at the beginning of the observation period

\begin{tabular}{lc}
\hline & $(1)$ \\
& $\log ($ voting share $)$ \\
\hline No. WT within municipality & $-0.510^{* *}$ \\
& $(0.222)$ \\
Population & -0.006 \\
& $(0.015)$ \\
Young HH & 0.000 \\
& $(0.002)$ \\
Unemployment & -0.007 \\
& $(0.006)$ \\
\hline Year FE & Yes \\
Municipality FE & Yes \\
Durbin-Wu-Hausman test & 0.02 \\
First stage F stat. & 7.65 \\
Obs. & 16,236 \\
\hline
\end{tabular}

Notes: Standard errors clustered at the municipality level in parenthesis. Estimation by 2SLS. The local adoption rate of wind power is considered endogenous. Instruments based on expected revenues of a WT according to the reference yield model. ${ }^{* * *} p<1 \%,{ }^{* *} p<5 \%,{ }^{*} p<10 \%$.

Table A13: Effect of the number and installed capacity of WTs on election outcomes for the Green Party at elections to the European Parliament

\begin{tabular}{lc}
\hline & $(1)$ \\
& $\log ($ green votes) \\
\hline No. WPS within municipality & $-0.243^{* * *}$ \\
& $(0.048)$ \\
Population & 0.002 \\
& $(0.002)$ \\
Young HH & -0.001 \\
& $(0.001)$ \\
Unemployment & -0.002 \\
& $(0.004)$ \\
\hline Year FE & Yes \\
Municipality FE & Yes \\
Durbin-Wu-Hausman test & 0.00 \\
First stage F stat. & 57.40 \\
Obs. & 20,076 \\
\hline
\end{tabular}

Notes: Standard errors clustered at the municipality level in parenthesis. Estimation by 2SLS. The local adoption rate of wind power is considered endogenous. Instruments based on expected revenues of a WT according to the reference yield model. The period under investigation covers the elections 2009 to 2014 . ${ }^{* * *} p<1 \%,{ }^{* *} p<5 \%,{ }^{*} p<10 \%$. 
Table A14: Local Commercial Tax Base and WTs

\begin{tabular}{|c|c|c|c|}
\hline & $\begin{array}{c}(1) \\
\text { D. } \log (\text { taxbase })\end{array}$ & $\begin{array}{l}\text { (2) } \\
\text { D. } \log (\text { taxbase - } \\
\text { top } 5 \% \text { removed })\end{array}$ & $\begin{array}{l}\qquad(3) \\
\text { D. } \log (\text { taxbase - } \\
\text { top and bottom } 5 \% \\
\text { removed) }\end{array}$ \\
\hline LD.No. WTs within municipality & $\begin{array}{l}0.111^{*} \\
(0.067)\end{array}$ & $\begin{array}{l}0.140^{*} \\
(0.078)\end{array}$ & $\begin{array}{l}0.149^{* *} \\
(0.071)\end{array}$ \\
\hline $\begin{array}{l}\text { Durbin-Wu-Hausman test } \\
\text { First stage F stat. } \\
\text { Obs. }\end{array}$ & $\begin{array}{c}0.04 \\
29.53 \\
41419\end{array}$ & $\begin{array}{c}0.04 \\
26.86 \\
38966\end{array}$ & $\begin{array}{c}0.02 \\
27.41 \\
37633\end{array}$ \\
\hline
\end{tabular}

Notes: Standard errors clustered at the municipality level in parenthesis. Estimation by 2SLS. The number of WTs is lagged by one year and is considered endogenous. Instruments based on expected revenues of a WT according to the reference yield model. Regression is estimated in first differences and includes year fixed effects. Commercial tax base is tax revenues divided by tax rate. To mitigate the effect of outliers, we trim the commercial tax base values at various thresholds. Point estimates are in a similar range when trimming at thresholds in between the displayed one. ${ }^{* * *} p<1 \%,{ }^{* *} p<5 \%,{ }^{*} p<10 \%$. 
Download ZEW Discussion Papers from our ftp server:

http://ftp.zew.de/pub/zew-docs/dp/

or see:

https://www.ssrn.com/link/ZEW-Ctr-Euro-Econ-Research.html

https://ideas.repec.org/s/zbw/zewdip.html

$$
\text { // }
$$

IMPRINT

ZEW - Leibniz-Zentrum für Europäische Wirtschaftsforschung GmbH Mannheim

ZEW - Leibniz Centre for European

Economic Research

L 7,1 68161 Mannheim · Germany

Phone +49621 1235-01

info@zew.de·zew.de

Discussion Papers are intended to make results of ZEW research promptly available to other economists in order to encourage discussion and suggestions for revisions. The authors are solely responsible for the contents which do not necessarily represent the opinion of the ZEW. 